\title{
Super-enhancers: a new frontier for epigenetic modifiers in cancer chemoresistance
}

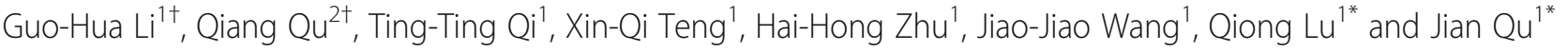

\begin{abstract}
Although new developments of surgery, chemotherapy, radiotherapy, and immunotherapy treatments for cancer have improved patient survival, the emergence of chemoresistance in cancer has significant impacts on treatment effects. The development of chemoresistance involves several polygenic, progressive mechanisms at the molecular and cellular levels, as well as both genetic and epigenetic heterogeneities. Chemotherapeutics induce epigenetic reprogramming in cancer cells, converting a transient transcriptional state into a stably resistant one. Super-enhancers (SEs) are central to the maintenance of identity of cancer cells and promote SE-driven-oncogenic transcriptions to which cancer cells become highly addicted. This dependence on SE-driven transcription to maintain chemoresistance offers an Achilles' heel for chemoresistance. Indeed, the inhibition of SE components dampens oncogenic transcription and inhibits tumor growth to ultimately achieve combined sensitization and reverse the effects of drug resistance. No reviews have been published on SE-related mechanisms in the cancer chemoresistance. In this review, we investigated the structure, function, and regulation of chemoresistance-related SEs and their contributions to the chemotherapy via regulation of the formation of cancer stem cells, cellular plasticity, the microenvironment, genes associated with chemoresistance, noncoding RNAs, and tumor immunity. The discovery of these mechanisms may aid in the development of new drugs to improve the sensitivity and specificity of cancer cells to chemotherapy drugs.
\end{abstract}

Keywords: Super-enhancer, Chemoresistance, Epigenetic reprogramming, Cancer, Therapy

\section{Background}

Cancer is presently a leading cause of death in 91 countries [1]. According to a report by the International Agency for Research on Cancer, there were 19.3 million new cases and nearly 10.0 million deaths from cancer in 2020 worldwide, and the incidence will increase in the future $[2,3]$. Beyond traditional chemotherapy approaches, new therapies, including targeted therapies and immunotherapy, have attracted scientific attention and produced clinical applications $[4,5]$, however, tumor heterogeneity

\footnotetext{
*Correspondence: christy_luq@csu.edu.cn; qujianstanley@csu.edu.cn ${ }^{\dagger}$ Guo-Hua Li and Qiang Qu contributed equally to this work. 'Department of Pharmacy, the Second Xiangya Hospital, Central South University; Institute of Clinical Pharmacy, Central South University, 139 Middle Renmin Road, Changsha, Hunan 410011, People's Republic of China Full list of author information is available at the end of the article
}

and resistance remain major obstacles to cancer treatment [6]. The resistance of tumor cells to chemotherapeutics (chemoresistance) is a critical challenge that oncological studies seek to understand and overcome [7].

Chemoresistance describes the reduced toxicity of chemotherapy drugs to tumor cells, which often leads to treatment failure. The responsiveness of tumor tissue to chemotherapy is determined by three main factors: the type of drug, the biological characteristics of the cancer cells, and the specific tumor microenvironment (TME) [8]. Most studies have focused on the internal factors of cancer cells, including cancer stem cells (CSCs), multidrug resistant proteins (MDRPs), autophagy, DNA damage repair, and epigenetic regulation $[9,10]$. Addressing

C C The Author(s). 2021 Open Access This article is licensed under a Creative Commons Attribution 4.0 International License, which permits use, sharing, adaptation, distribution and reproduction in any medium or format, as long as you give appropriate credit to the original author(s) and the source, provide a link to the Creative Commons licence, and indicate if changes were made. The images or other third party material in this article are included in the article's Creative Commons licence, unless indicated otherwise in a credit line to the material. If material is not included in the article's Creative Commons licence and your intended use is not permitted by statutory regulation or exceeds the permitted use, you will need to obtain permission directly from the copyright holder. To view a copy of this licence, visit http://creativecommons.org/licenses/by/4.0/ The Creative Commons Public Domain Dedication waiver (http://creativecommons.org/publicdomain/zero/1.0/) applies to the data made available in this article, unless otherwise stated in a credit line to the data. 
each decisive factor separately can help solve the problem of chemoresistance.

Epigenetic regulation is a way of regulating cell phenotype without changing DNA sequence. Recent studies suggested that chemoresistance is involved in both genetic and epigenetic heterogeneities and highlighted the role of epigenetic regulations [11-17]. Chemotherapeutics induce epigenetic reprogramming in cancer cells, converting a transient transcriptional state into a stably resistant one $[18,19]$.

Super-enhancers (SEs), first discovered by Young et al. in 2013, are a large cluster of multiple enhancers that can greatly promote gene expression [20]. Although the total number of genetic control elements can reach into the millions, only a few hundred SEs control the key genes for cell identity and function [21]. SEs are important elements in epigenetic regulation and play a key role in the occurrence and progression of diseases, particularly cancer, and they have the potential to be developed into new therapeutic targets and diagnostic markers [22, 23]. There have been multiple studies on the mechanisms by which SEs affect chemoresistance, providing a new direction to overcoming obstacles in chemotherapy, but there have been few summaries in this field. Thus, we focus here on the emerging role of epigenetics, particularly SEs, on chemoresistance through regulation of the formation of CSCs, cellular plasticity, the microenvironment, the genes associated with chemoresistance, and non-coding RNAs (ncRNAs), to contribute new ideas to improve the efficacy of chemotherapy.

\section{Chemoresistance overview}

\section{Intrinsic and acquired chemoresistance}

Chemoresistance may appear early in the process of tumorigenesis, whether de novo/primary (intrinsic) resistance or acquired/secondary resistance [24]. In intrinsic resistance, naive tumors do not produce a response to first-line chemotherapy in the initial treatment, whereas in acquired resistance, tumors are initially sensitive to chemotherapy, but it later fails to elicit a response [25]. Intrinsic resistance is selective, and it is related to genetic instability and tissue-specific chemoresistancerelated gene expression [26]. Acquired resistance results from drug induction, meaning that the drug triggers transcription and signaling pathways related to apoptosis and anti-apoptosis [27, 28]. Some studies have shown that chemoresistance is the result of random mutations but is nevertheless drug specific [29-31]. There are also some similarities in gene regulation between intrinsic resistance and acquired resistance, including autophagy, mutation of target proteins, and the overexpression of MDRPs [32, 33]. Both intrinsic and acquired resistance may exhibit multidrug and cross-resistance to agents that are structurally and pharmacologically diverse [34].
Tumor heterogeneity in resistance development has attracted more interest lately. Tumor heterogeneity is at the foundation of intrinsic and acquired chemoresistance, which can refer to patient heterogeneity, intertumor and intratumor cellular heterogeneity, genomic heterogeneity including mutations and gene fusion, and epigenetic heterogeneity with inherent differences between cell populations, as well as the possibility of therapy-induced epigenetic changes [35]. Due to the heterogeneity of tumors on the molecular and cellular levels, many mechanisms can coexist within tumors to induce chemotherapeutic resistance $[35,36]$.

\section{Mechanisms of chemoresistance}

The development of chemoresistance involves several mechanisms at the molecular and cellular levels [11]. The complex mechanisms that cross-talk and interact with each other in chemoresistance are founded in the pharmacokinetics and pharmacodynamics of chemotherapy drugs [11] (Fig. 1). The factors that affect the pharmacokinetics (absorption, distribution, metabolism, and excretion) of chemotherapeutic drugs include drug transporter-mediated change in drug influx/efflux, exosome-mediated drug export, subcellular drug compartmentalization and redistribution, and altered drug metabolism (which involves changes in drug interaction, inactivation, detoxification, and aberrant drugmetabolizing enzymes) [37, 38]. The mechanisms of pharmacodynamic chemoresistance include aberrant cell signaling, dysregulation in target expression and function, high-frequency mutations that target enzymes or change their catalytic function, genetic instability, oxidative stress, mitochondrial metabolic reprogramming, changes to the microenvironment, cellular reprogramming and phenotypic plasticity, inefficient apoptosis, and DNA repair [11, 37, 38]. Multiple biomolecular mechanisms are involved in the development of chemoresistance in cancer cells, including, but not limited to, CSCs, overexpression of MDRPs (e.g., P-glycoprotein; P-gp), dysregulation of apoptosis, TME, DNA damage repair, and epigenetic dysregulation [9].

Epigenetics refers to genetic changes in cell phenotypes that have nothing to do with changes in DNA sequences; the word is often used to describe the regulation of chromatin during DNA replication, transcription, and repair [39]. Related mechanisms include DNA methylation, histone modification, ncRNAs, and nucleosome positioning [40, 41]. DNA methylation leads to tighter chromatin, which inhibits gene expression. Conversely, acetylation modification increases chromatin accessibility and changes the nucleosome positioning to promote gene expression [42].

There is growing evidence that chemoresistance is not only related to genetic changes but is also influenced by 


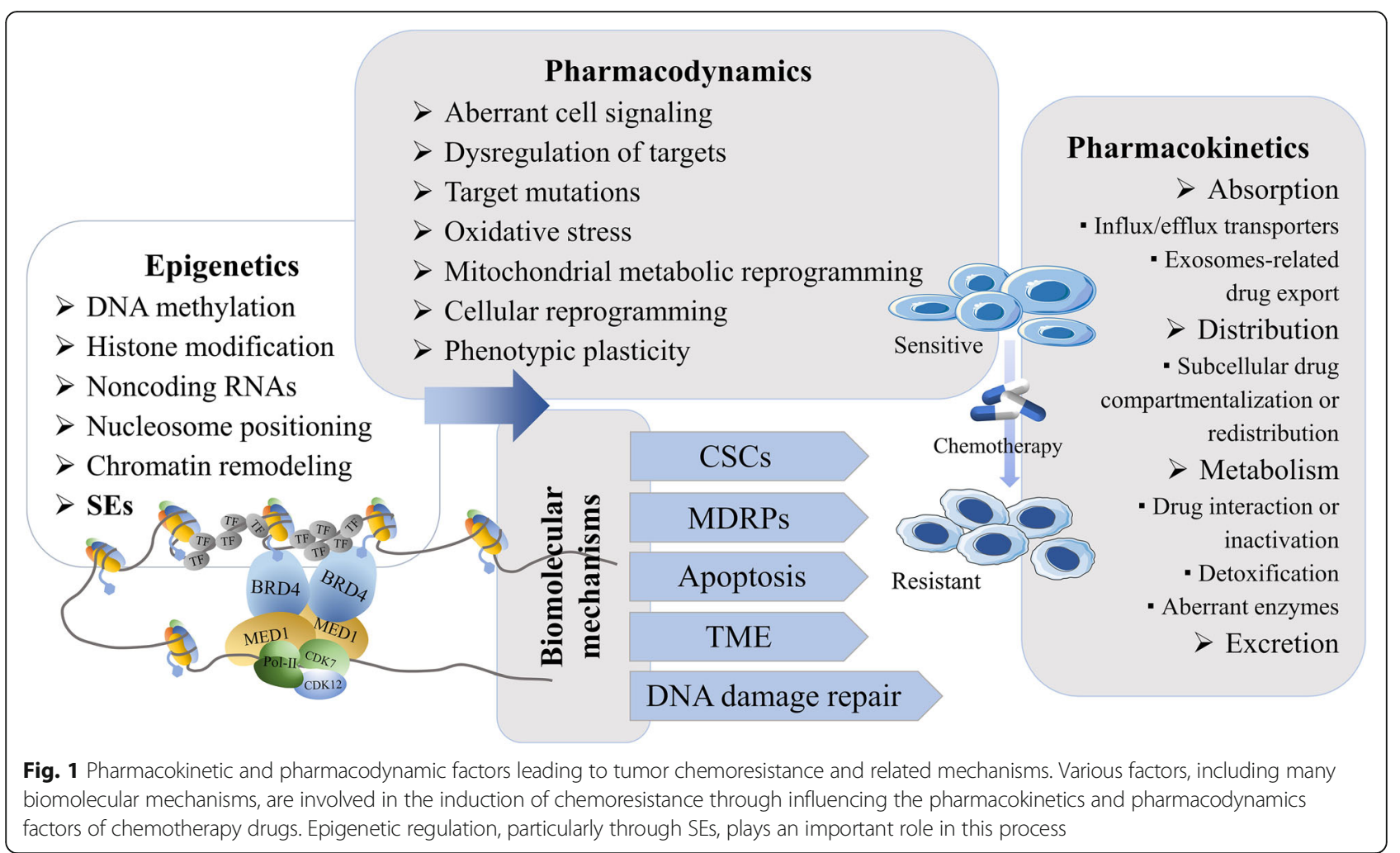

epigenetic regulation. Epigenetics has shed light on the elaborative cellular machinery involved in both tumor development and chemoresistance [11, 43]. The epigenetic landscape of cancer cells includes both heterogeneity and plasticity, as well as associated alterations [44]. Chemosensitive tumors that respond to primary chemotherapy can relapse but still respond to second-line chemotherapy, in a pattern that is attributable to heterogenicity and the relatively stable epigenetic state, while chemoresistant clones within a chemosensitive tumor may accrue temporal epigenetic changes during chemotherapy that then would change to a stable chemoresistant epigenetic state $[43,44]$. Chemotherapeutics induce epigenetic reprogramming in cancer cells, converting a transient transcriptional state to a stably resistant one $[19,45]$. Further, genetic changes, such as mutations in the regions of epigenetic regulating factors, can induce epigenetic aberrations, including changes in DNA methylation, histone covalent modifications, nucleosome repositioning, and SE landscape changes [46].

ncRNA refers to RNA that does not encode a protein, including ribosomal RNA, transfer RNA (tRNA), small nuclear RNA, small nucleolar RNA, microRNA, long noncoding RNA (lncRNA), circular RNA, and ncRNAs with unknown functions [47]. ncRNAs play a vital role in gene regulation, either by participating in base complementary pairing, or by acting as scaffolds or molecular chaperones for chromatin regulation [48]. Enhancer RNAs (eRNAs) and SE RNAs (seRNAs), transcribed by enhancers or SEs, in turn regulate the activity of enhancers or SEs through a variety of mechanisms, such as interacting with RNA polymerase II (RNA pol-II), promoting histone acetylation, and increasing transcription factor (TF) recruitment and chromatin accessibility [49-51].

The mechanism of epigenetics in tumor tolerance has been confirmed by multiple studies. DNA methylation downregulates the expression of antigen processing and presentation molecules, such as MHC I and Fas, leading to immune escape and reducing the sensitivity of the tumor cells to immunotherapy [52]. Histone demethylation can alter the chromatin state so that the cells dynamically survive drug exposure, that is, a single cell is in a transient and reversible tolerant state [53]. Similarly, epigenetic modifications also occur in CSCs, where DNA methylation and histone modifications regulate the activity of key signaling pathways, including wnt $/ \beta$-catenin, Hedgehog, and Notch, and the expression of ATP-binding cassette transporter proteins [54]. Moreover, ncRNAs also play an important role in the chemoresistance of various cancers, such as hepatocellular carcinoma (HCC) [55], colorectal cancer [56, 57], gastric cancer [58], lung cancer [59], and pancreatic cancer [60].

Many reviews have described the role that epigenetics plays in chemoresistance [12, 43, 44], but there is still insufficient detail on the function of SEs in chemoresistance. In the following sections, we describe the general 
components of SEs, followed by a detailed discussion of the potential association between SE aberrations and the mechanisms of chemoresistance.

\section{Structures and functions of SEs Concept and structures of SEs}

The enhancer is a non-coding cis-regulatory element, bounded by TFs, cofactors, mediators, and RNA Pol-II, that is responsible for transcription regulation in the human genome [61]. SEs are a large cluster of enhancers with a length of $8-20 \mathrm{~kb}$ that are enriched in more TFs, cofactors, mediators, RNA Pol-II, and histone H3 lysine27 acetylation (H3K27ac) than typical enhancers [21]. Cyclindependent kinase 7 (CDK7) and bromodomain-containing protein 4 (BRD4) are also important components of SEs and are enriched in SE regions [62]. High signals of H3K27ac and histone H3 lysine4 methylation (H3K4me1) usually represent active enhancers, and H3K27ac ChIPseq is widely used to identify SEs [63].

SEs strongly upregulate the expression of target genes by forming a physically interacting SE-promoter loop consisted of SEs, target genes, TFs, cofactors, mediators and RNA Pol-II, which spatially narrows the distance between SE and the promoter through cohesion [64]. Interestingly, the target gene is usually located either downstream or upstream of the SE, indicating that the regulation of SE is directionless [65]. Moreover, the distance between the SE and its target gene is uncertain, and SE usually acts through distant chromatin interactions [66]. Therefore, it may be that SEs simultaneously regulate the expression of multiple genes and may not follow rules of proximity [67]. ncRNAs transcribed from the SE region mediated by RNA Pol-II are called eRNAs [68]. Studies have shown that these eRNAs promote the formation of the SE-promoter loop and contribute to SE activity [69, 70] (Fig. 2a). Various TFs may occupy the SE region, among which some core TFs could regulate their own expression through SE-promoter interaction, thus forming a core transcriptional regulatory circuitry (CRC) [71, 72]. The CRC model can help us to better understand the role of SE in cell type-specific transcriptional regulation (Fig. 2b).

The three-dimensional (3D) conformation of chromatin influences gene expression and biological processes since DNA is packed in chromatin [73]. Studies have shown that the 3D organization of chromatin is dynamic in the regulation process of gene expression, and $3 \mathrm{C}$ (chromosome conformation capture) and its extended technologies including 4C (circularized chromosome conformation capture), 5C (chromosome conformation capture carbon copy) and Hi-C (high-throughput chromosome conformation capture) are often used for conformation research of chromatin [74].
SEs are usually located in the SE domains (SDs), specifically within the topologically associating domain (TAD) [75]. TADs, regions enriched in chromatin interactions, are composed of contact domains and multiple subTADs containing dense genes and inhibitory and activating chromatin signatures [76]. TADs are chromatin loop architectures formed in the process of genome organization, and are basic units of 3D nuclear organization, the properties and functions of which are affected by the 3D conformation of chromatin [77-79]. Architectural proteins, architectural protein binding sites, tRNAs, short interspersed nuclear elements and housekeeping genes form the boundaries of TADs that play a role of insulator and guarantee the interactions of distant elements $[77,80]$. CCCT C-binding factor (CTCF) is an important architectural protein that can associate with proteins such as transcription factor IIIC, condensins and cohesins to build a TAD boundary at a specific genomic location, thereby preventing cross-site interactions [81]. Insulated by the strong boundaries with lower chromatin interaction frequencies, SEs can only target genes within the SDs, thus preventing abnormal SE-promoter interactions and transcriptional activation [80, 82]. In addition, mediated by lowcomplexity disordered regions or intrinsically disordered regions, SEs can form membraneless phase-separated structures, which concentrate biologically and physically similar proteins or other molecules, thus enabling efficient transcription [83]. The transcriptional coactivators BRD4 and mediator of RNA Pol-II transcription subunit 1 (MED1) were found to form condensates at SEs, thereby compartmentalizing and concentrating the transcription apparatus [84]. Moreover, eRNAs serve as a scaffold for SE phase separation [69]. Hnisz et al. established a phase separation model to explain the transcriptional control of SEs, which is helpful for us to understand the formation and function of SEs as well [85] (Fig. 2c).

\section{Roles of SEs in cancer \\ SEs control cell identity}

The factors that induce the formation of oncogenic SEs include DNA mutations and indels, chromatin rearrangements, changes in the $3 \mathrm{D}$ structure of the chromosome, and viral infections [86]. In the unique SEpromoter 3D loop and phase separation structure, SEs usually show greater transcriptional activation ability than typical enhancers [21]. SEs are also more sensitive to perturbations and thus can be targeted by small molecular inhibitors such as JQ1, a BRD4 inhibitor, and THZ1, a CDK7 inhibitor [87]. Previous studies have shown that SEs regulate the expression of cell-typespecific genes $[88,89]$. Therefore, SEs can be considered powerful cis-regulatory elements, defining cell identity and conferring cell fate. 


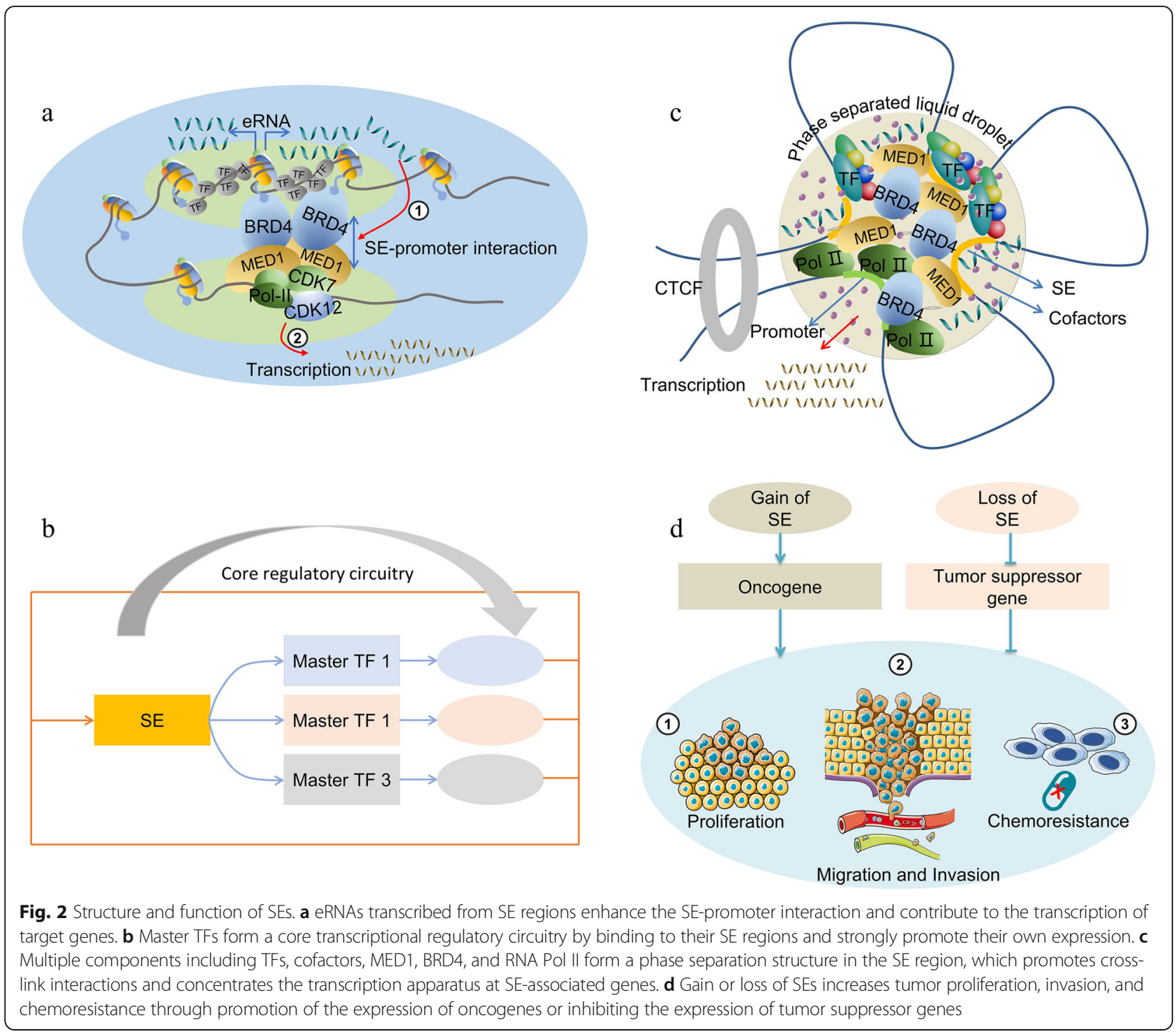

It has been reported that SEs contribute to the maintenance of stem cell identity, including ESCs [83], hairfollicle stem cells [90], and hematopoietic stem cells [91]. In addition, SEs can regulate uterine development [63], T cell development [92], and myogenic differentiation [93]. However, the recurrent gain or loss of SEs usually leads to diseases, including neurodegenerative disease [94], autoimmune disease [75], and various cancers [20]. SEs undergo dynamic remodeling in the progression of cell lineage [95]. The formation of SEs for key TFs associated with the control of cell identities, such as Oct4, Sox 2 and Nanog, can reprogram cell fate through CRCs in ESCs, even in cancer cells [21, 96]. Research by Denes Hnisz et al. showed that SEs have the potential to become biomarkers of specific cancers, which may provide references for the occurrence, diagnosis and treatment of cancers [20].
SEs drive tumorigenesis, tumor progression, and prognosis Aberrant gene transcription driven by SEs can always lead to tumorigenesis, tumor progression, and prognosis [97]. Therefore, SEs can be used as effective biomarkers for cancer diagnosis, treatment, and prognosis. Moreover, the identification of cancer-specific SEs can help us to find new critical oncogenes and uncover novel mechanisms for different cancers. On this occasion, many SE-related databases, including dbSUPER [98], SEA version 3.0 [99], and SEdb [100], have been established to facilitate SE exploration. Due to the development of genome-wide epigenetic data, tumor epigenetic markers such as SEs have been attracting more and more attention for their use in predicting tumor progression, prognosis/disease free survival, chemo sensitivity/chemoresistance, and recurrence. 
In $\mathrm{HCC}$, an important regulatory axis related to $\mathrm{SE}$ was found: transcription factor 4 (TCF4) occupies the SE region and induces extensive interactions between $\mathrm{SE}$ and the AJUBA promoter, which strongly promotes AJUBA expression and increases cancer metastasis [101]. In addition to directly regulating the expression of coding genes directly, SEs can also regulate the expression of ncRNAs in cancer [102]. seRNAs are transcribed from the SE and can recruit TFs, promote the formation of SE-promoter loops, direct chromatin accessibility, and regulate SE acetyltransferase activity [51]. Jiao et al. found that heparinase eRNA enhances chromatin looping between the SE and promoter in several cancer cell lines, promoting tumorigenesis in vitro and in vivo [103]. Klf6 is a gene responsible for tumorigenesis, and the loss of the Klf6 SE was found to inhibit the proliferation of liver cancer cells by upregulating miR-1301 [104]. lncRNA HCCL5 is an SE-driven gene that confers the malignant phenotypes of liver cancer cells [105]. LINC00162, an SE lncRNA, was highly expressed in bladder cancer cells and tissues, which can promote progression of bladder cancer [106]. Our team constructed prognostic models for five -genes associated with SEs for osteosarcoma patients and multiple myeloma patients, which accurately predict the prognosis of these cancer patients $[107,108]$.

Studies that use the CRC model and are focused on master TFs and SEs are gradually growing in number. Zhang was recently the first to study SE-associated CRC transcriptional control in lung adenocarcinoma: master TFs ELF3, EHF, and TGIF1 were found to co-occupy the SE region and promote each other's expression through the formation of CRC, which induces the malignant progression of lung adenocarcinoma [109]. Similarly, in Ewing sarcoma, KLF15, TCF4, and NKX2-2 have been identified as the master TFs containing both EWS-FLI1 binding motif and SE peaks [110]. Importantly, these three CRC TFs co-regulate the PI3K/AKT and MAPK signaling pathways to promote the aggressiveness of Ewing sarcoma [110].

It is worth mentioning that although SEs play an important role in stem cell identity and contribute to the development of regenerative medicine, once they are hijacked by cancer cells, their transcriptional balance is broken and the number of CSCs increases. For example, osteosarcoma-specific SEs promote tumor stemness by directly activating the expression of leukemia-inhibitory factor (LIF) [111]. In glioblastoma, the formation of a new SE-promoter loop upregulates the expression of genes associated with tumor stemness, such as CDK6 and SOX2 [112, 113]. In addition, SEs may also play a role in the possible response of cancer cells to chemotherapy [114, 115]. Many genes may be related to drug resistance, including characteristic genes of CSCs and some transporters, are regulated by SEs. Besides, certain factors can induce the appearance of chemoresistance by regulating the modification of histone, BRD4 and CDK activity, and the formation of SEs. Details of the mechanisms are shown in Fig. 2d.

\section{SE-driven mechanisms of chemoresistance}

Recent studies have shown that SEs are related to the chemoresistance of various cancers, including small-cell lung cancer (SCLC), ovarian cancer and adenocarcinoma, breast cancer, glioblastoma, and so forth $[45,116,117]$. Moreover, the sensitivity of chemotherapy can be restored by small molecule epigenetic inhibitors of SEs [45]. In the following sections, we discuss the potential association between SE-driven mechanisms and cancer chemoresistance, such as through the regulation of the formation of CSCs, cellular plasticity, the microenvironment, genes associated with chemoresistance, ncRNAs, and tumor immunity (Table 1) (Fig. 3).

\section{SEs and CSCs in chemoresistance}

SEs can affect the development of chemoresistance by affecting the formation and markers of CSCs. According to the literature on neuroblastoma, the SE-related genes MEOX2, SIX1, and SIX4, among others, are involved in CSC identity and can lead to increased resistance [21, 118]. The retinoic acid receptor-related orphan receptor gamma (ROR $\gamma$ ) is a nuclear hormone receptor that has emerged as a key regulator of stem cells. In pancreatic adenocarcinoma, the expression of $R O R \gamma$ increases with cancer progression, and its blockade via genetic or pharmacologic approaches profoundly depletes the CSC pool and inhibits human and mouse tumor propagation by partly suppressing an SE-associated oncogenic network [117]. The high aldehyde dehydrogenase (ALDH) activity due to ALDH1A1 expression contributes to chemotherapy resistance and tumor relapse. Studies have shown that BETi can inhibit ALDH activity by abolishing BRD4-mediated ALDH1A1 expression through SE elements and its associated eRNAs, thereby inhibiting the growth of cisplatin-treated ovarian cancer cells [119]. For their part, SOX2 and SOX9 are stem factors that play an important role in the acquired resistance of squamous cell carcinoma (SCC) to cisplatin: the detailed mechanism of this feature is the switch from SOX2+ to SOX9+ mediated by SE remodeling [120]. A study of genome-wide RNAi screening has shown that salinomycin and JQ1 have synergy effects in the inhibition of breast CSCs, and JQ1 may be a potential smallmolecule drug to overcome the resistance of cancer cells to chemotherapy [121]. 
Table 1 Functions of SEs in chemoresistance

\begin{tabular}{|c|c|c|c|c|c|}
\hline Directions & Cancer & Resistant drugs & $\begin{array}{l}\text { Induction } \\
\text { methods }\end{array}$ & SE related genes & References \\
\hline \multirow{7}{*}{$\begin{array}{l}\text { Related genes } \\
\text { downstream }\end{array}$} & Ovarian cancer & Cisplatin & Stepwise method & SOX9 $\rightarrow$ WNT5A & {$[45]$} \\
\hline & $\mathrm{SCLC}$ & $\begin{array}{l}\text { Doxorubicin, cisplatin, } \\
\text { etoposide }\end{array}$ & De novo & $\begin{array}{l}\mathrm{IRF} 1 \rightarrow \mathrm{MYB}, \mathrm{SP} 1 \rightarrow \\
\mathrm{ABCC1}\end{array}$ & [116] \\
\hline & BRAF-mutant colon cancer & Vemurafenib & De novo & MAPK pathway & [139] \\
\hline & $\mathrm{MCL}$ & Ibrutinib, lenalidomide & / & $\begin{array}{l}\text { BCR pathway, IKZF-MYC } \\
\text { axis }\end{array}$ & [140] \\
\hline & TNBC & Neoadjuvant chemotherapy & De novo & MYCN & [141] \\
\hline & NSCLC & TRAIL, cisplatin & De novo & $c-F L I P, X I A P$ & [142] \\
\hline & $\mathrm{HCC}$ & Sorafenib & / & ZNF263 & [143] \\
\hline \multirow[t]{4}{*}{ CSCs } & Pancreatic adenocarcinoma & Gemcitabine & De novo & RORY & [117] \\
\hline & Ovarian cancer & Cisplatin & Cisplatin IC20 & ALDH & [119] \\
\hline & Squamous cell carcinoma & Cisplatin & Cisplatin IC50 & $\mathrm{SOX} 2+\rightarrow \mathrm{SOX} 9+$ & [120] \\
\hline & Breast cancer & Salinomycin & De novo & / & [121] \\
\hline \multirow[t]{4}{*}{ ncRNAs } & Pan-cancer & / & De novo & Linc00152 & [148] \\
\hline & Prostate cancer & Enzalutamide & / & CHPT1 & [149] \\
\hline & Prostate cancer & / & / & MANCR & {$[150]$} \\
\hline & Colorectal cancer & Oxaliplatin & $2 \mu \mathrm{M}$ oxaliplatin & MALAT1 & [152] \\
\hline \multirow[t]{3}{*}{ Microenvironment } & Clear cell renal cell carcinoma & / & / & $C X C$ & [134] \\
\hline & Squamous cell carcinoma & / & / & CXCL1/2 & [161] \\
\hline & $\begin{array}{l}\text { Pancreatic ductal } \\
\text { adenocarcinoma }\end{array}$ & / & / & / & [135] \\
\hline \multirow[t]{2}{*}{ Cellular plasticity } & Breast cancer & / & / & EN1, TBX18, TCF4 & [131] \\
\hline & Basal cell carcinoma & Vismodegib & De novo & $\begin{array}{l}\text { Vismodegib and Wnt } \\
\text { pathway }\end{array}$ & [132] \\
\hline
\end{tabular}

SCLC small cell lung cancer, MCL mantle cell Lymphoma, TNBC triple-negative breast cancer, NSCLC non-small cell lung cancer, HCC hepatocellular carcinoma, TRAI $L$ tumor necrosis factor-related apoptosis-inducing ligand

\section{SEs and cellular plasticity in chemoresistance}

Cellular plasticity refers to changes in cell genetic molecules and phenotypes, and it is a mechanism of cancer occurrence and progression [122]. The emergence of plasticity is related to the stimulation of the microenvironment, changes in cell-signaling pathways, and biochemical characteristics [123]. The most common type of cell plasticity is epithelial-mesenchymal transition (EMT) [124], which is involved in the migration, invasion, and chemotherapy resistance of cancer cells [122, 125]. Other types of plasticity, such as the transition to neuroendocrine phenotype and CSC, also appear in resistance to chemotherapy, such as SCLC and ovarian cancer [126-128].

SEs can regulate the plasticity of cancer cells and may lead to chemoresistance. The different cell subtypes of pancreatic ductal adenocarcinoma are inseparable from the modulation of SEs. Targeting SEs affects the transition from classic to basal subtypes, thereby controlling the progression of malignant tumors $[129,130]$. Three TFs, namely, TBX18, EN1, and TCF4, are involved in regulating the transition in breast cancer cells from the luminal type to the basal type [131]. Resistance to Hedgehog pathway inhibitor (vismodegib) is associated with the cell identity switch of the remaining cells from the hair follicle bulge to interfollicular epidermis and isthmus mixture driven by the changing chromatin state and SE remodeling in research on basal cell carcinoma conducted by Biehs et al., and the simultaneous inhibition of vismodegib and the Wnt pathway can alleviate this dilemma [132].

\section{SEs and the microenvironment in chemoresistance}

SEs are sensitive to changes in the microenvironment. A study of hair follicle stem cells found that SOX9 acts as a sensor of the microenvironment for SEs and promotes chromatin remodeling, thus providing a support for chromatin dynamics in wound repair and cell plasticity [95]. External signals in the microenvironment drive SErelated chromatin remodeling, thereby affecting cell lineage and fate, and BMP protein plays an important role in this process [133]. Likewise, SEs regulate the production of CXC chemokines in clear cell renal cell carcinoma, which mediates the release of inflammatory 


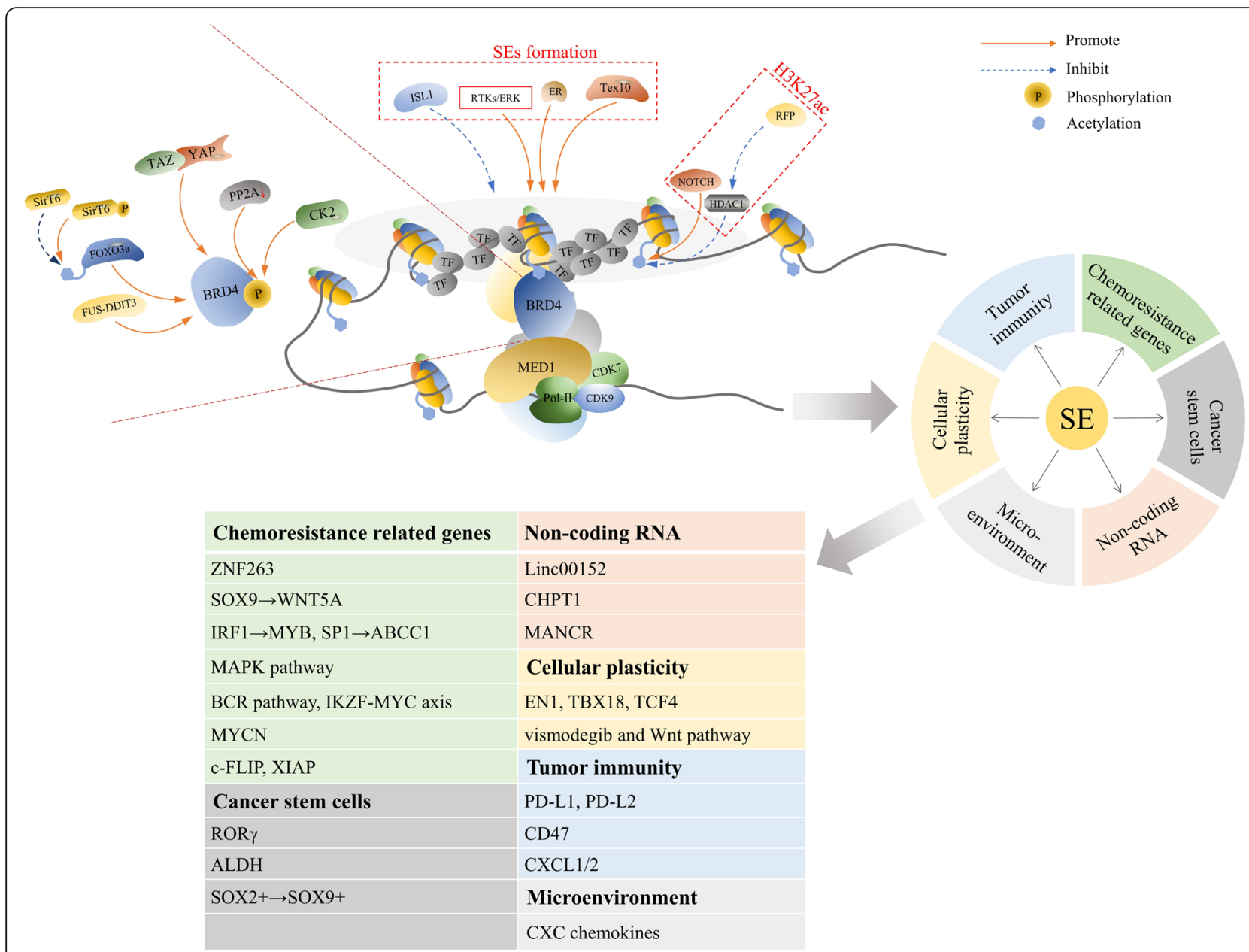

Fig. 3 The role that SEs play in tumor chemoresistance and the factors that influence the activity of the SE complex. SEs can induce tumor chemoresistance by regulating molecular biological factors such as the formation of CSCs, cellular plasticity, the microenvironment, genes associated with chemoresistance, tumor immunity, and ncRNAs. A variety of complex components are involved in regulating the activity of SEs, including H3K27ac, BRD4, and CDKs, through which many molecules affect SE formation and activity in the process of acquiring chemoresistance. Related inhibitors can also restrain the occurrence of chemoresistance

factors in TME and promotes inflammation and lung metastasis [134]. A study of pancreatic ductal adenocarcinoma showed that fibroblasts in the TME are upregulated by SEs, and triptolide, which acts as a CDK7 inhibitor, can downregulate SE-related genes and promote sensitivity to chemotherapy [135].

\section{SEs and genes associated with chemoresistance}

Many genes regulated by SEs reduce the sensitivity of tumor cells to chemotherapy, either by increasing drug effluxes or by changing drug targets and other mechanisms. SOX9, a key TF related to chondrogenesis [136], hair follicles [137], and neural progenitors stemness [138], has been confirmed to be upregulated in cisplatinresistant ovarian cancer cell lines due to the regulation of SEs, and the depletion of the regulation of SEs can lead to the downregulation of TFs associated with chemoresistance, including MAF, cMYC, ZNF430, E2F7, and KLF6, as well as the improvement of sensitivity to cisplatin [45]. Bao et al. identified SEs related to chemoresistance in SCLC through integrated highthroughput analyses and confirmed associated genes in resistance to doxorubicin, cisplatin, and etoposide, including IRF1 and SP1, which regulate the expression of MDRPs, such as MYB and ABCC1 [116]. In BRAFmutant colon cancer, cell resistance to vemurafenib (a BRAF inhibitor) is a result of the feedback activation for the MAPK signaling pathway by SEs, and an additional combination of related inhibitors can reverse this phenomenon [139]. In mantle cell lymphoma (MCL), SEs regulate genes related to cell survival through BRD4, such as B cell receptor (BCR) signaling and IKZF-MYC axis, and the inhibition of BRD4 may overcome MCL resistance to ibrutinib (BCR pathway inhibitor) or lenalidomide (IKZF inhibitor) [140]. MYCN, regulated by SEs, plays a key role in the tolerance of triple-negative breast 
cancer (TNBC) to neoadjuvant chemotherapy, where cells with high MYCN expression are more sensitive to BET inhibitors, such that the combined inhibition of BET and MEK produces a synergistic killing effect on TNBC cells [141]. The early suppression of SE-related genes, $c-F L I P$, and XIAP, by BET inhibitor, is effective for overcoming the resistance to tumor necrosis factorrelated apoptosis-inducing ligand and cisplatin in research on non-small cell lung cancer [142]. ZNF263 is the most significant endoplasmic reticulum stressspecific SE bounding TF and has been upregulated in HCC patients and cell lines. ZNF263 knockdown results in decreased proliferation, apoptosis resistance, and chemoresistance, which implies that SE-related genes are important for chemoresistance in cancers [143].

\section{SEs and ncRNAs in chemoresistance}

ncRNAs are important regulators in the development of the chemoresistance of various cancers, such as HCC [55, 144], colorectal cancer [56, 57], gastric cancer [58], lung cancer [59], and pancreatic cancer [60, 145]. Many studies have shown that SEs can regulate the activity of ncRNAs and change tumor progression [105, 146, 147]. SEs may trigger drug resistance through ncRNAs [102]. In a study of the role of Linc00152 in pan-cancer, it was reported that SE50407 can affect drug resistance by modulating the level of Linc00152 and then promoting AKT pathway activity [148]. CHPT1 is a tumorpromoting gene that catalyzes the synthesis of phosphatidylcholine and regulates choline metabolism. In prostate cancer cells that are resistant to enzalutamide, the enhancer element in CHPT1 SE transcribes IncRNA, namely eRNA, binds to BRD4, and regulates CHPT1 SE activity and CHPT1 expression, mediating androgenindependent drug tolerance [149]. The lncRNA MANCR has the same effect on prostate cancer, and JQ1 can downregulate MANCR to reduce cell migration and invasion [150]. Moreau et al. proved that hypoxia, a central mechanism in chemoresistance, can trigger oxaliplatin resistance in colorectal cancer by activating SEs and SE-derived ncRNA, MALAT1, which promotes CDH1 expression, and EMT [151, 152]. Similarly, SEderived ncRNA, UCA1, may have anti-apoptotic effects through the Hippo/YAP1 pathway to induce chemoresistance in epithelial ovarian cancer [153].

\section{SEs and tumor immunity in chemoresistance}

The tumor immune microenvironment (TIME) is an important contributor to the occurrence and development of cancer [154]. TIME is the main obstacle and key determinant of chemotherapy or immunotherapy checkpoint inhibitors [8], which can inhibit immune-mediated antitumor effects [155]. Moreover, cancer immune evasion is a major stumbling block to the design of effective anticancer immune therapeutic strategies [156]. Cancer cells can escape T-cell-mediated cellular cytotoxicity by exploiting inhibitory programmed cell-death protein 1 (PD-1)/programmed cell-death 1 ligand 1 (PD-L1) immune checkpoint [157]. Recent studies have shown that SEs play an important role in tumor immune escape and TIME.

$\mathrm{Xu}$ et al. identified a key SE (PD-L1L2-SE) located between the encoding regions for PD-L1 and PD-L2 using bioinformatic analyses and genetic manipulation. The genetic deletion of PD-L1L2-SE causes a loss of immune evasion in tumor cells and renders them sensitive to $\mathrm{T}$ cell killing [158]. CD47 is a cell surface molecule that inhibits phagocytosis by binding to its receptor, SIRPa, on macrophages and other immune cells [159]. Betancur et al. showed that cancers can evolve SEs to drive CD47 overexpression to escape immune surveillance [160]. In SCC, stem cells express and secrete CXCL1 and CXCL2 by establishing SEs, which send a signal to the immune system to consolidate cell stability in the TIME [161]. Inhibition of related SEs may increase the sensitivity of cancer cells to immunotherapy or overcome chemoresistance by changing the TIME.

\section{Regulation of SEs complex activity to overcome chemoresistance of cancer}

The phenomenon of cancer chemoresistance and low mutation frequency demonstrates the importance of epigenetic modification. Increasing evidence implies that chemotherapy can induce SE-driven transcriptional programs to maintain the chemoresistant state $[18,45]$. Therefore, targeted inhibitors that specifically block the interaction between SE regions and their corresponding complexes can rescue upregulated oncogene- and chemoresistance-related genes [162, 163].

In relation to the different protein components in the regulatory pathway, SE inhibitors are divided into multiple types: BRD4 inhibitors, histone acetylation inhibitors, CDK inhibitors, and gene-editing technology [20, 62]. Because the first three are mostly small-molecule inhibitors that can effectively prevent the interaction of SEs and the complex and have greater feasibility, they are more widely used [164]. Furthermore, the extensive effects of master TFs, histone modification, and cofactors make it difficult to target them, while mediator complexes such as CDK7 and BRD4 are relatively characteristic [62]. Here, we summarized the chemoresistant mechanisms involved with SEs, as well as the effects of the SE-related inhibitors on reverse drug resistance and combined sensitization (Tables 2 and 3).

\section{BRD4 inhibitors}

Bromodomain and extra terminal (BET) protein family, including BRD1, BRD2, BRD3, BRD4, and BRDt, can 
Table 2 Regulation of SE activity in chemoresistance

\begin{tabular}{|c|c|c|c|c|c|c|}
\hline Complex & Cancer & Resistant drugs & $\begin{array}{l}\text { Induction } \\
\text { methods }\end{array}$ & SE-associated genes & Mechanisms & References \\
\hline \multirow[t]{3}{*}{$\mathrm{H} 3 \mathrm{~K} 27 \mathrm{ac}$} & Glioblastoma & Temozolomide & $\begin{array}{l}50 \mu \mathrm{M} \\
\text { temozolomide }\end{array}$ & / & Transient resistant state & [183] \\
\hline & Glioblastoma & Temozolomide & / & $\mathrm{RFP} / \mathrm{HDAC} 1$ & Inhibit H3K27ac & [184] \\
\hline & Leukemia & / & / & Notch & Promote H3K27ac & {$[186,187]$} \\
\hline \multirow[t]{8}{*}{ BRD4 } & Breast cancer & AKTi & $\begin{array}{l}\text { Stepwise } \\
\text { method }\end{array}$ & SirT6, FOXO3a & BRD4/FOXO3a/CDK6 axis & {$[170]$} \\
\hline & Melanoma & Vemurafenib & $\begin{array}{l}1 \mu \mathrm{M} \\
\text { vemurafenib }\end{array}$ & YAP/TAZ & $\begin{array}{l}\text { Transcription addition mediated by } \\
\text { YAP/TAZ through BRD4 }\end{array}$ & [171] \\
\hline & Myeloma & IMiDs & / & PP2A & Hyper pBRD4 & [172] \\
\hline & TNBC & BETi & $\begin{array}{l}\text { Stepwise } \\
\text { method }\end{array}$ & $\mathrm{CK} 2, \mathrm{PP} 2 \mathrm{~A}$ & pBRD4 increase MED1 recruitment & [173] \\
\hline & T cell leukemia & GSI & $1 \mu \mathrm{M}$ GSI & $\mathrm{NDME} \rightarrow \mathrm{BDME}$ & Transition from NDME to BDME & {$[174]$} \\
\hline & Liposarcoma & Trabectedin & de novo & FUS-DDIT3 & Formation of $C R C$ & {$[175]$} \\
\hline & PDAC & $5-\mathrm{FU}$ & $\begin{array}{l}\text { Stepwise } \\
\text { method }\end{array}$ & HMGA2 & / & {$[176]$} \\
\hline & $\mathrm{MCL}$ & $\begin{array}{l}\text { Ibrutinib, venetoclax } \\
\text { and palbociclib }\end{array}$ & De novo & E3-ubiquitin ligase & / & {$[177]$} \\
\hline \multirow[t]{3}{*}{ CDK } & B cell lymphoma & ABT-199 & 20 nM ABT-199 & BCL2 18q21 loss & Drug-tolerant "persister" state & [191] \\
\hline & Leukemia cells & BETi & / & RNA pol-II, MYC & / & [193] \\
\hline & $\begin{array}{l}\text { Anaplastic thyroid } \\
\text { carcinoma }\end{array}$ & Doxorubicin & De novo & DNA damage repair & $\begin{array}{l}\text { Downregulation of DNA damage } \\
\text { repair }\end{array}$ & [192] \\
\hline \multirow{4}{*}{$\begin{array}{l}\text { SEs } \\
\text { formation }\end{array}$} & TNBC & Trametinib & / & RTKs/ERK & SEs de novo formation & [194] \\
\hline & $\begin{array}{l}\text { Hepatocellular } \\
\text { carcinoma }\end{array}$ & Sorafenib, cisplatin & $\begin{array}{l}5 \mu \mathrm{M} / \mathrm{L} \\
\text { sorafenib/ } \\
\text { cisplatin }\end{array}$ & Tex10 & Formation of ESC related SEs & [195] \\
\hline & ER+ breast cancer & Endocrine therapy & Doxycycline & ER-ligand-independent & Increased combination of ER and SEs & [196] \\
\hline & ER+ breast cancer & Endocrine therapy & $\begin{array}{l}\text { Endocrine } \\
\text { therapy }\end{array}$ & $\begin{array}{l}\text { Endogenous } \\
\text { cholesterol } \\
\text { biosynthesis }\end{array}$ & Epigenetic reprogramming & [197] \\
\hline
\end{tabular}

TNBC triple-negative breast cancer, PDAC pancreatic ductal adenocarcinoma, $M C L$ mantle cell lymphoma, AKTi AKT inhibitor, IMiDs immunomodulatory drugs, $B E T i$ BET bromodomain inhibitors, GSI gamma-secretase inhibitor, NDME notch-dependent MYC enhancer, BDME BRD4-dependent MYC enhancer, RNA pol-II RNA polymerase-II, TSA trichostatin, ESC embryonic stem cell, CRC core transcription regulatory circuitry

recognize histone proteins by binding to acetylated lysine residues and play a role of reader in epigenetic regulation $[165,166]$. Among these, BRD4 is an important element in cancer biology and can interact with SEs. A colocalization of BRD4 and MED1 appears at H3 acetylation chromatin sites, particularly H3K27 [166], so the factors that influencing BRD4 and MED1 also affect the transcriptional activity regulated by SEs.

BRD4 inhibitors can be divided into JQ1 and its derivatives, 3,5-dimethylisoxazole derivatives, 2-thiazolidinone derivatives, and others, based on their chemical structure [167]. JQ1 is the first bromodomain and extra-terminal domain (BET) inhibitor (BETi) that competitively inhibits the binding of BRD4 to chromatin, leading to cell cycle arrest and increased apoptosis $[167,168]$. Many in vivo and in vitro studies have shown that JQ1 is effective against a variety of cancers [169]. In this review, we found that BETi can reverse drug resistance and has a synergistic effect with some chemotherapy drugs.

AKT inhibitor (AKTi) is a class of drugs targeted to breast cancer, but, its frequent use could disturb the regulatory mechanisms of common tumor cells and induce drug resistance [170]. As has been found in related research, AKTi treatment increases the acetylation of FOXO3a by dephosphorylating SirT6 and induces the combination of FOXO3a and BRD4. This series of reactions increases the transcription of CDK6, which promotes the development of drug resistance to AKTi [170]. The BRD4 inhibitors JQ1 and MS417 improve the growth-suppressive effect mediated by $\mathrm{AKTi}$, and the BRD4/FOXO3a/CDK6 axis passivates AKT inhibition in luminal breast cancer [170]. The resistance of melanoma cells to BRAF inhibitor (vemurafenib) is associated with transcription addiction, and the mechanism of this 
Table 3 Reversal of chemoresistance

\begin{tabular}{|c|c|c|c|c|}
\hline Target & Inhibitors & Cancers & Resistant drugs or sensitized drugs & References \\
\hline \multirow[t]{13}{*}{ BRD4 } & JQ1 & Ovarian cancer & Cisplatin & {$[45,119]$} \\
\hline & & NSCLC & TRAIL, cisplatin & [142] \\
\hline & & Breast cancer & Salinomycin & [121] \\
\hline & & Breast cancer & AKTi & [170] \\
\hline & & Melanoma & Vemurafenib & [171] \\
\hline & & PDAC & $5-\mathrm{FU}$ & [176] \\
\hline & I-BET151 & $\mathrm{MCL}$ & Ibrutinib, lenalidomide & [140] \\
\hline & & TNBC & Trametinib & [194] \\
\hline & I-BET762 & NSCLC & TRAlL, cisplatin & [142] \\
\hline & OTX-015 & NSCLC & TRAIL, cisplatin & [142] \\
\hline & SR2211 & Pancreatic adenocarcinoma & Gemcitabine & [117] \\
\hline & ARV-771 & $\mathrm{MCL}$ & Ibrutinib, venetoclax, palbociclib & [177] \\
\hline & MS417 & Breast cancer & AKTi & [170] \\
\hline $\mathrm{H} 3 \mathrm{~K} 27 \mathrm{ac}$ & TSA & Glioblastoma & Temozolomide & [183] \\
\hline CDK7 & THZ1 & B cell lymphoma & ABT-199 & [191] \\
\hline CDK12 & THZ531 & Anaplastic thyroid carcinoma & Doxorubicin & [192] \\
\hline
\end{tabular}

NSCLC non-small cell lung cancer, PDAC pancreatic ductal adenocarcinoma, $M C L$ mantle cell lymphoma, TNBC triple-negative breast cancer, $A K T i$ AKT inhibitor, TRAIL tumor necrosis factor-related apoptosis-inducing ligand

resistance is that YAP/TAZ induces the recruitment of SEs to BRD4 and RNA Pol-II and activates the expression of growth-regulating genes [171]. In myeloma cells sensitive to immunomodulatory drugs (IMiDs), the depletion of IKZF1/IKZF3 caused SE instability and reduced the binding of BRD4. However, in resistant cells, the binding of BRD4 to SEs was unaffected, which could be attributed to the decrease in PP2A activity and the increase in BRD4 phosphorylation [172]. In addition, the phosphorylation of BRD4 is also related to BETi tolerance in TNBC cells, the mechanisms for which include a decrease in PP2A activity and an increase in CK2 activity and MED1 recruitment [173]. In $T$ cell leukemia, Notch1 could activate the expression of downstream genes by binding to SEs of MYC. However, in cell lines that are resistant to a gamma-secretase inhibitor, the inhibition of Notch1 cannot cause the downregulation of MYC. A study by Yashiro-Ohtani et al. indicated that this is due to the transition of MYC SEs from Notch1dependent (NDME) to BRD4-dependent MYC enhancer [174] (Fig. 3).

Studies have shown that FUS-DDIT3 has regulatory effects on SEs through interaction with BRD4, which may participate in the resistance of liposarcoma cells to trabectedin and CRC formation, and BET inhibitors can effectively overcome this limitation in treatment [175]. Furthermore, the blockage of BRD4 sensitizes 5-FU toxicity to pancreatic ductal adenocarcinoma [176]. ARV771 , a proteolysis-targeting chimera of BET protein has stronger activity in interfering with BET protein than $\mathrm{BETi}$, which may be promising for the overcoming of the resistance of MCL cells to ibrutinib, venetoclax, and palbociclib [177].

\section{Histone acetylation}

Chemical modifications of DNA and histone proteins in chromatin could modulate gene expression through changing conformations and altering transcriptional complex recruitment. Common chemical methods of modifying histone proteins include acetylation/deacetylation and methylation/demethylation [166]. Acetylated histones destabilize nucleosomes, thereby increasing the accessibility of chromatin to TFs [178, 179]. Acetylation modification of chromatin histones is jointly regulated by histone acetyltransferase and histone deacetylase (HDAC) enzymes; the two are in a state of dynamic balance [180]. High-density H3K27ac is a sign that identifies SEs, which leads to a rapid response of target genes to various signals $[21,181,182]$.

Studies have shown that resistance is associated with histone acetylation. Rabé et al. confirmed that the transient resistance state to temozolomide in glioblastoma cells is related to high levels of histone acetylation and chromatin remodeling, and the sensitive and resistant state shows lower acetylated histone levels. The combined application of temozolomide and HDAC inhibitor trichostatin could prevent the transition from a transient to a resistant state [183]. Similarly, a review of the 
resistance mechanism of glioblastoma cells to temozolomide indicated that disrupting the formation of RFP/ HDAC1 complex would interfere with the function of cis-regulatory-element, controlled by H3K27ac, and then it would overcome the chemoresistance induced by SErelated genes [184, 185]. In leukemia and T-cell acute lymphoblastic leukemia, the tolerance of chemotherapy by cancer cells is related to the regulation of Notch 1 protein to H3K27 acetylation. The mutation of Notch1 would suppress H3K27ac marks on SEs and disrupt downstream MYC expression, which may show how resistant cells maintain growth under drug pressure [186, 187] (Fig. 3).

\section{CDKs}

The appearance of SEs in cancer cells leads to high transcription output and high transcription addiction, which result in stronger responses to transcriptional inhibition [188]. CDKs are an important category of protein, which can bind to cyclin proteins and regulate the cell cycle, playing an important role in gene transcription [189]. These features make them indispensable for the regulation of SEs activity and overcoming chemoresistance. Studies have shown that SEs activate transcriptions are inseparable from the recruitment of CDK7-containing TFIIH (a transcription initiation complex), CDK9containing p-TEFb (a transcription extension complex), and CDK12 [86, 97, 190]. Therefore, inhibitors that target CDKs can reduce SE activity, thereby inhibiting the occurrence and progression of cancer and reversing chemoresistance.

According to research on B cell lymphoma, the emergence of a drug-tolerant "persister" state is associated with SE remodeling in resistance to ABT-199, a target drug of BCL-2, and the inhibitor of CDK7 (THZ1) could significantly reverse this effect [191]. One study showed that the CDK12 inhibitor THZ531 can inhibit transcriptional extension and downregulate DNA damage repair, thereby increasing the sensitivity of anaplastic thyroid carcinoma cells to doxorubicin [192]. The combination of the BETi inhibitor and the CDK7 inhibitor leads to the synthetic lethality in leukemia cells resistant to BETi, which is associated with the RNA pol-II activity regulated by SEs [193] (Fig. 3).

\section{Other links to SE activity}

In the case of drug resistance, the appearance and regulation of SEs are also affected by other factors. As a response to trametinib, a MEK1/2 inhibitor, adaptive resistance takes place in TNBC as a result of de novo SE formation [194]. Tex10 upregulates ESC-related SEs in sorafenib- and cisplatin-resistant cell lines, which is an important chemoresistance mechanism for HCC [195]. Studies have shown that the ER-ligand-binding domain is mutated in $\mathrm{ER}^{+}$breast cancer cells that are resistant to endocrine therapy, and these cells acquire ligandindependent growth. During the exploration of the mechanism of this phenomenon, it was found that the interaction between ER and SEs in the mutant cells has increased [196]. Furthermore, epigenetic reprogramming for endocrine therapy activates endogenous cholesterol biosynthesis, which promotes the constitutive activation of ER $\alpha$ in drug-resistant cells [197].

Moreover, inhibitors of oncogenes can both directly influence the expression of oncogenes and block genome-wide oncogene enhancers and SEs activation as well, along with downstream transcriptional signaling. A recent study found that darolutamide, an inhibitor of the androgen receptor, antagonizes androgen signaling by blocking enhancers and SE activation in prostate cancer [198]. The new drugs involved in SE-related oncogenes' transcriptional regulation may produce important results for chemotherapeutic resistance. The remodeling of SEs in drug-resistant cells may also be related to the downregulation of certain genes. In ovarian cancer, ISL1, a lineage determinant, is downregulated when cells are continuously stimulated by cisplatin, mediating the increase in CSCs and chemoresistance induced by SE plasticity [199] (Fig. 3).

\section{Perspective and summary}

Due to the differing genetic/epigenetic backgrounds and heterogeneity of tumors, the efficacy of chemotherapy varies widely across patients. Understanding the changing epigenetic landscape during chemotherapy and the dynamic interaction between the genetic and epigenetic machinery in response to chemotherapy are inevitable for assessing the clinical efficacy of chemotherapy. Within the new frontier of epigenetic modifiers, more and more evidence has shown the important role of SEs in tumor development and chemotherapy resistance.

Epigenetic gene signatures, particularly SEs, have attracted increased interest lately with regard to the molecular subtypes of tumors and their prediction of tumor recurrence, the prognosis of tumor patients, and chemotherapy resistance in different cancers. Mapping the epigenome and monitoring epi-biomarkers (such as SEs) using genome-wide analyses at clinical settings before, during, and after treatment and at relapse will help evaluate and adjust the treatment approach and design personalized epigenetic therapy [11]. Despite the continuous emergence of relevant research, chemotherapy resistance remains a complex process that needs to be explored in depth. We may still need to conduct more research upstream and investigate more initial mechanisms to clarify the reasons for the generation and regulation of resistance-related SEs. Furthermore, related 
inhibitors require clinical trials to prove their effectiveness and safety for overcoming chemoresistance.

\section{Conclusions}

In conclusion, SEs are central to the maintenance of identity of cancer cells and promote SE-drivenoncogenic transcriptions to which cancer cells become highly addicted. Chemotherapeutics induce SEs reprogramming in cancer cells, converting a transient transcriptional state into a stably resistant one. Aberrant transcriptional regulation of SEs plays important roles in epigenetic mechanisms of cancer chemoresistance via the formation of CSCs, cellular plasticity, the microenvironment, genes associated with chemoresistance, ncRNAs, and tumor immunity. This dependence on SEdriven transcription to maintain chemoresistance offers an Achilles' heel for chemoresistance. Indeed, the inhibition of SE components dampens oncogenic transcription and inhibits tumor growth to ultimately achieve combined sensitization and reverse the effects of drug resistance. The research on the SEs in tumorigenesis and chemoresistance may help find new drugs to overcome chemoresistance from the bench to the bedside.

\section{Abbreviations}

TME: Tumor microenvironment; CSC: Cancer stem cells; MDRP: Multi-drug resistant protein; SE: Super-enhancer; TF: Transcription factor; ESC: Embryonic stem cell; ncRNA: non-coding RNA; tRNA: transfer RNA; InCRNA: long noncoding RNA; eRNA: enhancer RNA; seRNA: super-enhancer RNA; RNA polII: RNA polymerase-II; H3K27ac: Histone H3 lysine27 acetylation; CDK7: Cyclindependent kinase 7; BRD4: Bromodomain-containing protein 4; H3K4me1: Histone H3 lysine4 methylation; CRC: Core transcriptional regulatory circuitry; SD: SE domain; TAD: Topologically associating domain; CTCF: CCCTC-binding factor; IDR: Intrinsically disordered region; MED1: Mediator of RNA Pol-II transcription subunit 1; TCF4: Transcription factor 4; RORy: Receptor-related orphan receptor gamma; ALDH: Aldehyde dehydrogenase; EMT: Epithelial-mesenchymal transition; SCLC: Small-cell lung cancer; MCL: Mantle cell lymphoma; BCR: B cell receptor; TNBC: Triplenegative breast cancer; HCC: Hepatocellular carcinoma; TIME: Tumor immune microenvironment; PD-1: Programmed cell-death protein 1; PDL1: Programmed cell death 1 ligand 1; SCC: Squamous cell carcinoma; BET: BRD and extraterminal domain; BETi: BET protein inhibitor; AKTi: AKT inhibitor; IMiDs: Immunomodulatory drugs; HDAC: Histone deacetylase

\section{Acknowledgements}

Not applicable.

\section{Authors' contributions}

$J Q$ and QQ had the idea for the article, GHL, TTQ, QQ and XQT performed the literature search and data collection, GHL, JQ, QL, TTQ, and XQT drafted the manuscript, JQ and QL critically revised the work. All authors modified and approved the final manuscript.

\section{Funding}

This work was supported by the National Natural Science Foundation of China (No. 82073944), Scientific Research Project of Hunan Health Commission (No. 202113010170), and the Hunan Provincial Department of Finance Grant (No. 2019-93 and 2018-92).

Availability of data and materials Available.

\section{Declarations}

Ethics approval and consent to participate

Not applicable.

\section{Consent for publication}

Not applicable.

\section{Competing interests}

The authors declare that they have no competing interests.

\section{Author details}

${ }^{1}$ Department of Pharmacy, the Second Xiangya Hospital, Central South University; Institute of Clinical Pharmacy, Central South University, 139 Middle Renmin Road, Changsha, Hunan 410011, People's Republic of China. ²Department of Pharmacy, Xiangya Hospital, Central South University, Changsha 410008, People's Republic of China.

Received: 15 March 2021 Accepted: 5 May 2021

Published online: 19 May 2021

\section{References}

1. Bray F, Ferlay J, Soerjomataram I, Siegel RL, Torre LA, Jemal A. Global cancer statistics 2018: GLOBOCAN estimates of incidence and mortality worldwide for 36 cancers in 185 countries. CA Cancer J Clin. 2018;68:394-424.

2. Ferlay J, Soerjomataram I, Dikshit R, Eser S, Mathers C, Rebelo M, et al. Cancer incidence and mortality worldwide: sources, methods and major patterns in GLOBOCAN 2012. Int J Cancer. 2015;136:E359-86.

3. The International Agency for Research on Cancer. https://www.iarc.who.int/ featured-news/latest-global-cancer-data-cancer-burden-rises-to-19-3-millionnew-cases-and-10-0-million-cancer-deaths-in-2020/. Accessed 15 Oct 2020.

4. Naylor EC, Desani JK, Chung PK. Targeted therapy and immunotherapy for lung Cancer. Surg Oncol Clin N Am. 2016;25:601-9.

5. Menderes G, Black J, Schwab CL, Santin AD. Immunotherapy and targeted therapy for cervical cancer: an update. Expert Rev Anticancer Ther. 2016;16: 83-98.

6. Zugazagoitia J, Guedes C, Ponce S, Ferrer I, Molina-Pinelo S, Paz-Ares L. Current challenges in Cancer treatment. Clin Ther. 2016;38:1551-66.

7. Khot VM, Salunkhe AB, Pricl S, Bauer J, Thorat ND, Townley H. Nanomedicine-driven molecular targeting, drug delivery, and therapeutic approaches to cancer chemoresistance. Drug Discov Today. 2020;26(3):724-39.

8. Vasan N, Baselga J, Hyman DM. A view on drug resistance in cancer. Nature. 2019:575:299-309.

9. Wu Q, Yang Z, Nie Y, Shi Y, Fan D. Multi-drug resistance in cancer chemotherapeutics: mechanisms and lab approaches. Cancer Lett. 2014;347: 159-66

10. Li YJ, Lei YH, Yao N, Wang CR, Hu N, Ye WC, et al. Autophagy and multidrug resistance in cancer. Chin J Cancer. 2017;36:52.

11. Ponnusamy L, Mahalingaiah PKS, Singh KP. Epigenetic reprogramming and potential application of epigenetic-modifying drugs in acquired chemotherapeutic resistance. Adv Clin Chem. 2020;94:219-59.

12. Quagliano A, Gopalakrishnapillai A, Barwe SP. Understanding the mechanisms by which epigenetic modifiers avert therapy resistance in Cancer. Front Oncol. 2020;10:992.

13. Zhou Y, Sun W, Qin Z, Guo S, Kang Y, Zeng S, et al. LncRNA regulation: new frontiers in epigenetic solutions to drug chemoresistance. Biochem Pharmacol. 2020;104(10):114228.

14. Takezawa K, Okamoto I, Okamoto W, Takeda M, Sakai K, Tsukioka S, et al. Thymidylate synthase as a determinant of pemetrexed sensitivity in nonsmall cell lung cancer. Br J Cancer. 2011;104:1594-601.

15. Quagliano A, Gopalakrishnapillai A, Barwe SP. Epigenetic drug combination overcomes osteoblast-induced chemoprotection in pediatric acute lymphoid leukemia. Leuk Res. 2017:56:36-43.

16. Kim K, Skora AD, Li Z, Liu Q, Tam AJ, Blosser RL, et al. Eradication of metastatic mouse cancers resistant to immune checkpoint blockade by suppression of myeloid-derived cells. Proc Natl Acad Sci U S A. 2014;111: 11774-9.

17. Wang W, Oguz G, Lee PL, Bao Y, Wang P, Terp MG, et al. KDM4B-regulated unfolded protein response as a therapeutic vulnerability in PTEN-deficient breast cancer. J Exp Med. 2018;215:2833-49. 
18. Sengupta S, George RE. Super-enhancer-driven transcriptional dependencies in Cancer. Trends Cancer. 2017;3:269-81.

19. Shaffer SM, Dunagin MC, Torborg SR, Torre EA, Emert B, Krepler C, et al. Rare cell variability and drug-induced reprogramming as a mode of cancer drug resistance. Nature. 2017:546:431-5.

20. Hnisz D, Abraham BJ, Lee TI, Lau A, Saint-Andre V, Sigova AA, et al. Superenhancers in the control of cell identity and disease. Cell. 2013;155:934-47

21. Whyte WA, Orlando DA, Hnisz D, Abraham BJ, Lin CY, Kagey MH, et al. Master transcription factors and mediator establish super-enhancers at key cell identity genes. Cell. 2013;153:307-19.

22. Niederriter AR, Varshney A, Parker SC, Martin DM. Super enhancers in cancers, complex disease, and developmental disorders. Genes (Basel). 2015; 6:1183-200.

23. Thandapani P. Super-enhancers in cancer. Pharmacol Ther. 2019;199:129-38.

24. Gottesman MM. Mechanisms of cancer drug resistance. Annu Rev Med. 2002;53:615-27.

25. Kartal-Yandim M, Adan-Gokbulut A, Baran Y. Molecular mechanisms of drug resistance and its reversal in cancer. Crit Rev Biotechnol. 2016;36:716-26.

26. Kohno K, Uchiumi T, Niina I, Wakasugi T, Igarashi T, Momii Y, et al. Transcription factors and drug resistance. Eur J Cancer. 2005;41:2577-86.

27. Nebert DW. Transcription factors and cancer: an overview. Toxicology. 2002; 181-182:131-41.

28. Karamouzis MV, Gorgoulis VG, Papavassiliou AG. Transcription factors and neoplasia: vistas in novel drug design. Clin Cancer Res. 2002;8:949-61.

29. Nikolaou M, Pavlopoulou A, Georgakilas AG, Kyrodimos E. The challenge of drug resistance in cancer treatment: a current overview. Clin Exp Metastasis. 2018;35:309-18.

30. Jaffrezou JP, Chen KG, Duran GE, Kuhl JS, Sikic Bl. Mutation rates and mechanisms of resistance to etoposide determined from fluctuation analysis. J Natl Cancer Inst. 1994;86:1152-8.

31. Dumontet C, Duran GE, Steger KA, Beketic-Oreskovic L, Sikic Bl. Resistance mechanisms in human sarcoma mutants derived by single-step exposure to paclitaxel (Taxol). Cancer Res. 1996;56:1091-7.

32. Buttigliero C, Tucci M, Bertaglia V, Vignani F, Bironzo P, Di Maio M, et al. Understanding and overcoming the mechanisms of primary and acquired resistance to abiraterone and enzalutamide in castration resistant prostate cancer. Cancer Treat Rev. 2015;41:884-92.

33. Caffo O, Veccia A, Maines F, Bonetta A, Spizzo G, Galligioni E. Potential value of rapid prostate-specific antigen decline in identifying primary resistance to abiraterone acetate and enzalutamide. Future Oncol. 2014;10:985-93.

34. Glasspool RM, Teodoridis JM, Brown R. Epigenetics as a mechanism driving polygenic clinical drug resistance. Br J Cancer. 2006;94:1087-92.

35. Januskeviciene I, Petrikaite V. Heterogeneity of breast cancer: the importance of interaction between different tumor cell populations. Life Sci. 2019;239:117009

36. Horowitz M, Esakov E, Rose P, Reizes O. Signaling within the epithelial ovarian cancer tumor microenvironment: the challenge of tumor heterogeneity. Ann Transl Med. 2020;8:905.

37. Mansoori B, Mohammadi A, Davudian S, Shirjang S, Baradaran B. The different mechanisms of Cancer drug resistance: a brief review. Adv Pharm Bull. 2017;7:339-48.

38. Housman G, Byler S, Heerboth S, Lapinska K, Longacre M, Snyder N, et al. Drug resistance in cancer: an overview. Cancers (Basel). 2014;6:1769-92.

39. Berger SL, Kouzarides T, Shiekhattar R, Shilatifard A. An operational definition of epigenetics. Genes Dev. 2009:23:781-3.

40. Sharma S, Kelly TK, Jones PA. Epigenetics in cancer. Carcinogenesis. 2010;31: 27-36.

41. Dawson MA, Kouzarides T. Cancer epigenetics: from mechanism to therapy. Cell. 2012;150:12-27.

42. Lao W, Grady WM. Epigenetics and colorectal cancer. Nat Rev Gastroenterol Hepatol. 2011;8:686-700

43. Brown R, Curry E, Magnani L, Wilhelm-Benartzi CS, Borley J. Poised epigenetic states and acquired drug resistance in cancer. Nat Rev Cancer. 2014; 14:747-53.

44. Wilting $\mathrm{RH}$, Dannenberg $\mathrm{JH}$. Epigenetic mechanisms in tumorigenesis, tumor cell heterogeneity and drug resistance. Drug Resist Updat. 2012;15: 21-38.

45. Shang S, Yang J, Jazaeri AA, Duval AJ, Tufan T, Lopes Fischer N, et al. Chemotherapy-induced distal enhancers drive transcriptional programs to maintain the Chemoresistant state in ovarian Cancer. Cancer Res. 2019;79: 4599-611.
46. You JS, Jones PA. Cancer genetics and epigenetics: two sides of the same coin? Cancer Cell. 2012;22:9-20

47. Anastasiadou E, Jacob LS, Slack FJ. Non-coding RNA networks in cancer. Nat Rev Cancer. 2018;18:5-18.

48. Wang KC, Chang HY. Molecular mechanisms of long noncoding RNAs. Mol Cell. 2011:43:904-14.

49. Mousavi K, Zare H, Dell'orso S, Grontved L, Gutierrez-Cruz G, Derfoul A, et al. eRNAs promote transcription by establishing chromatin accessibility at defined genomic loci. Mol Cell. 2013;51:606-17.

50. Mao R, Wu Y, Ming Y, Xu Y, Wang S, Chen X, et al. Enhancer RNAs: a missing regulatory layer in gene transcription. Sci China Life Sci. 2019;62: 905-12.

51. Wu M, Shen J. From super-enhancer non-coding RNA to immune checkpoint: frameworks to functions. Front Oncol. 2019;9:1307.

52. Gomez S, Tabernacki T, Kobyra J, Roberts P, Chiappinelli KB. Combining epigenetic and immune therapy to overcome cancer resistance. Semin Cancer Biol. 2020;65:99-113.

53. Sharma SV, Lee DY, Li B, Quinlan MP, Takahashi F, Maheswaran S, et al. A chromatin-mediated reversible drug-tolerant state in cancer cell subpopulations. Cell. 2010;141:69-80.

54. Toh TB, Lim JJ, Chow EK. Epigenetics in cancer stem cells. Mol Cancer. 2017 ; $16: 29$

55. Ding B, Lou W, Xu L, Fan W. Non-coding RNA in drug resistance of hepatocellular carcinoma. Biosci Rep. 2018;38(5):BSR20180915.

56. Wei L, Wang $X$, LV L, Zheng Y, Zhang N, Yang M. The emerging role of noncoding RNAs in colorectal cancer chemoresistance. Cell Oncol (Dordr). 2019;42:757-68.

57. Neve B, Jonckheere N, Vincent A, Van Seuningen I. Epigenetic regulation by IncRNAs: an overview focused on UCA1 in colorectal Cancer. Cancers (Basel). 2018;10(11):440.

58. Luo YJ, Huang QM, Ren Y, Liu ZL, Xu CF, Wang H, et al. Non-coding RNA in drug resistance of gastric cancer. World J Gastrointest Oncol. 2019:11:957-70.

59. Mondal P, Natesh J, Kamal MA, Meeran SM. Non-coding RNAs in lung Cancer Chemoresistance. Curr Drug Metab. 2019;20:1023-32.

60. Xiong G, Feng M, Yang G, Zheng S, Song X, Cao Z, et al. The underlying mechanisms of non-coding RNAs in the chemoresistance of pancreatic cancer. Cancer Lett. 2017;397:94-102.

61. Ong CT, Corces VG. Enhancer function: new insights into the regulation of tissue-specific gene expression. Nat Rev Genet. 2011;12:283-93.

62. Zheng $\mathrm{C}$, Liu M, Fan $\mathrm{H}$. Targeting complexes of super-enhancers is a promising strategy for cancer therapy. Oncol Lett. 2020;20:2557-66.

63. Jefferson WN, Kinyamu HK, Wang T, Miranda AX, Padilla-Banks E, Suen $A A$, et al. Widespread enhancer activation via ERa mediates estrogen response in vivo during uterine development. Nucleic Acids Res. 2018; 46:5487-503.

64. Ing-Simmons E, Seitan VC, Faure AJ, Flicek P, Carroll T, Dekker J, et al. Spatial enhancer clustering and regulation of enhancer-proximal genes by cohesin. Genome Res. 2015;25:504-13.

65. Furlong EEM, Levine M. Developmental enhancers and chromosome topology. Science. 2018:361:1341-5.

66. Wu C, Chen J, Liu Y, Hu X. Improved prediction of regulatory element using hybrid abelian complexity features with DNA sequences. Int J Mol Sci. 2019; 20(7):1704.

67. Poot R. The rules of successful speed dating are complex, even for superenhancers. Cell Stem Cell. 2018:22:477-8.

68. Hah N, Benner C, Chong LW, Yu RT, Downes M, Evans RM. Inflammationsensitive super enhancers form domains of coordinately regulated enhancer RNAs. Proc Natl Acad Sci U S A. 2015;112:E297-302.

69. Arnold PR, Wells AD, Li XC. Diversity and emerging roles of enhancer RNA in regulation of gene expression and cell fate. Front Cell Dev Biol. 2019;7:377.

70. Chen H, Liang H. A High-Resolution Map of Human Enhancer RNA Loci Characterizes Super-enhancer Activities in Cancer. Cancer Cell. 2020;38:701715.e705.

71. Saint-André V, Federation AJ, Lin CY, Abraham BJ, Reddy J, Lee TI, et al. Models of human core transcriptional regulatory circuitries. Genome Res. 2016;26:385-96.

72. Huang $M$, Chen $Y$, Yang $M$, Guo $A, X u Y, X u L$, et al. dbCoRC: a database of core transcriptional regulatory circuitries modeled by H3K27ac ChIP-seq signals. Nucleic Acids Res. 2018;46:D71-d77.

73. Zheng $\mathrm{H}$, Xie $\mathrm{W}$. The role of $3 \mathrm{D}$ genome organization in development and cell differentiation. Nat Rev Mol Cell Biol. 2019;20:535-50. 
74. Su JH, Zheng P, Kinrot SS, Bintu B, Zhuang X. Genome-scale imaging of the 3D organization and transcriptional activity of chromatin. Cell. 2020;182: 1641-59 e1626.

75. Yamagata K, Nakayamada S, Tanaka Y. Critical roles of super-enhancers in the pathogenesis of autoimmune diseases. Inflamm Regen. 2020;40:16

76. Cubenas-Potts C, Corces VG. Topologically associating domains: an invariant framework or a dynamic scaffold? Nucleus. 2015;6:430-4.

77. Dixon JR, Selvaraj S, Yue F, Kim A, Li Y, Shen Y, et al. Topological domains in mammalian genomes identified by analysis of chromatin interactions. Nature. 2012;485:376-80

78. McArthur E, Capra JA. Topologically associating domain boundaries that are stable across diverse cell types are evolutionarily constrained and enriched for heritability. Am J Hum Genet. 2021;108:269-83.

79. Kloetgen A, Thandapani P, Ntziachristos P, Ghebrechristos Y, Nomikou S, Lazaris $C$, et al. Three-dimensional chromatin landscapes in T cell acute lymphoblastic leukemia. Nat Genet. 2020;52:388-400.

80. Van Bortle K, Nichols MH, Li L, Ong CT, Takenaka N, Qin ZS, et al. Insulator function and topological domain border strength scale with architectural protein occupancy. Genome Biol. 2014;15:R82.

81. Ong CT, Corces VG. CTCF: an architectural protein bridging genome topology and function. Nat Rev Genet. 2014;15:234-46.

82. Gong Y, Lazaris C, Sakellaropoulos T, Lozano A, Kambadur P, Ntziachristos P, et al. Stratification of TAD boundaries reveals preferential insulation of super-enhancers by strong boundaries. Nat Commun. 2018;9:542.

83. Sun X, Ren Z, Cun Y, Zhao C, Huang X, Zhou J, et al. Hippo-YAP signaling controls lineage differentiation of mouse embryonic stem cells through modulating the formation of super-enhancers. Nucleic Acids Res. 2020;48: 7182-96.

84. Sabari BR, Dall'Agnese A, Boija A, Klein IA, Coffey EL, Shrinivas K, et al. Coactivator condensation at super-enhancers links phase separation and gene control. Science. 2018;361(6400):eaar3958.

85. Hnisz D, Shrinivas K, Young RA, Chakraborty AK, Sharp PA. A phase separation model for transcriptional control. Cell. 2017;169:13-23.

86. Jia Q, Chen S, Tan Y, Li Y, Tang F. Oncogenic super-enhancer formation in tumorigenesis and its molecular mechanisms. Exp Mol Med. 2020; 52(5):713-23.

87. Chen D, Zhao Z, Huang Z, Chen DC, Zhu XX, Wang YZ, et al. Super enhancer inhibitors suppress MYC driven transcriptional amplification and tumor progression in osteosarcoma. Bone Res. 2018;6:11.

88. Fox S, Myers JA, Davidson C, Getman M, Kingsley PD, Frankiewicz N, et al. Hyperacetylated chromatin domains mark cell type-specific genes and suggest distinct modes of enhancer function. Nat Commun. 2020; 11:4544

89. Ohkura N, Yasumizu Y, Kitagawa Y, Tanaka A, Nakamura Y, Motooka D, et al. Regulatory T Cell-Specific Epigenomic Region Variants Are a Key Determinant of Susceptibility to Common Autoimmune Diseases. Immunity. 2020:52:1119-1132.e1114.

90. Adam RC, Yang H, Ge Y, Infarinato NR, Gur-Cohen S, Miao Y, et al. NFI transcription factors provide chromatin access to maintain stem cell identity while preventing unintended lineage fate choices. Nat Cell Biol. 2020;22 640-50.

91. Bahr C, von Paleske L, Uslu W, Remeseiro S, Takayama N, Ng SW, et al. A Myc enhancer cluster regulates normal and leukaemic haematopoietic stem cell hierarchies. Nature. 2018;553:515-20.

92. Kitagawa $Y$, Ohkura N, Kidani $Y$, Vandenbon A, Hirota K, Kawakami R, et al. Guidance of regulatory $T$ cell development by Satb1-dependent superenhancer establishment. Nat Immunol. 2017;18:173-83.

93. Peng $X L$, So KK, He L, Zhao Y, Zhou J, Li Y, et al. MyoD- and FoxO3mediated hotspot interaction orchestrates super-enhancer activity during myogenic differentiation. Nucleic Acids Res. 2017;45:8785-805.

94. Alcalà-Vida R, Awada A, Boutillier AL, Merienne K. Epigenetic mechanisms underlying enhancer modulation of neuronal identity, neuronal activity and neurodegeneration. Neurobiol Dis. 2021;147:105155.

95. Adam RC, Yang H, Rockowitz S, Larsen SB, Nikolova M, Oristian DS, et al. Pioneer factors govern super-enhancer dynamics in stem cell plasticity and lineage choice. Nature. 2015;521:366-70.

96. Boyer LA, Lee TI, Cole MF, Johnstone SE, Levine SS, Zucker JP, et al. Core transcriptional regulatory circuitry in human embryonic stem cells. Cell. 2005; 122:947-56

97. Tang F, Yang Z, Tan Y, Li Y. Super-enhancer function and its application in cancer targeted therapy. NPJ Precis Oncol. 2020;4:2.
98. Khan A, Zhang X. dbSUPER: a database of super-enhancers in mouse and human genome. Nucleic Acids Res. 2016;44:D164-71.

99. Chen C, Zhou D, Gu Y, Wang C, Zhang M, Lin X, et al. SEA version 3.0: a comprehensive extension and update of the super-enhancer archive. Nucleic Acids Res. 2020;48:D198-d203.

100. Jiang Y, Qian F, Bai X, Liu Y, Wang Q, Ai B, et al. SEdb: a comprehensive human super-enhancer database. Nucleic Acids Res. 2019;47:D235-d243.

101. Zhang C, Wei S, Sun WP, Teng K, Dai MM, Wang FW, et al. Super-enhancerdriven AJUBA is activated by TCF4 and involved in epithelial-mesenchymal transition in the progression of hepatocellular carcinoma. Theranostics. 2020;10:9066-82.

102. Wang Y, Nie H, He X, Liao Z, Zhou Y, Zhou J, et al. The emerging role of super enhancer-derived noncoding RNAs in human cancer. Theranostics. 2020;10:11049-62.

103. Jiao W, Chen $Y$, Song $H$, Li D, Mei H, Yang F, et al. HPSE enhancer RNA promotes cancer progression through driving chromatin looping and regulating hnRNPU/p300/EGR1/HPSE axis. Oncogene. 2018;37:2728-45.

104. Ri K, Kim C, Pak C, Ri P, Om H. The KLF6 super enhancer modulates cell proliferation via MiR-1301 in human hepatoma cells. Microrna. 2020; 9:64-9.

105. Peng L, Jiang B, Yuan X, Qiu Y, Peng J, Huang Y, et al. Super-enhancerassociated long noncoding RNA HCCL5 is activated by ZEB1 and promotes the malignancy of hepatocellular carcinoma. Cancer Res. 2019;79:572-84.

106. Wang X, Zhang R, Wu S, Shen L, Ke M, Ouyang Y, et al. Super-Enhancer LncRNA LINC00162 Promotes Progression of Bladder Cancer. iScience. 2020; 23:101857.

107. Ouyang Z, Li G, Zhu H, Wang J, Qi T, Qu Q, et al. Construction of a fivesuper-enhancer-associated-genes prognostic model for osteosarcoma patients. Front Cell Dev Biol. 2020;8:598660.

108. Qi T, Qu J, Tu C, Lu Q, Li G, Wang J, et al. Super-enhancer associated fivegene risk score model predicts overall survival in multiple myeloma patients. Front Cell Dev Biol. 2020;8:596777.

109. Zhang T, Song X, Zhang Z, Mao Q, Xia W, Xu L, et al. Aberrant superenhancer landscape reveals core transcriptional regulatory circuitry in lung adenocarcinoma. Oncogenesis. 2020;9:92.

110. Shi $X$, Zheng $Y$, Jiang $L$, Zhou B, Yang W, Li L, et al. EWS-FLI1 regulates and cooperates with core regulatory circuitry in Ewing sarcoma. Nucleic Acids Res. 2020:48:11434-51.

111. Lu B, He Y, He J, Wang L, Liu Z, Yang J, et al. Epigenetic profiling identifies LIF as a super-enhancer-controlled regulator of stem cell-like properties in osteosarcoma. Mol Cancer Res. 2020;18:57-67.

112. Johnston MJ, Nikolic A, Ninkovic N, Guilhamon P, Cavalli FMG, Seaman S, et al. High-resolution structural genomics reveals new therapeutic vulnerabilities in glioblastoma. Genome Res. 2019;29:1211-22

113. Mack SC, Singh I, Wang X, Hirsch R, Wu Q, Villagomez R, et al. Chromatin landscapes reveal developmentally encoded transcriptional states that define human glioblastoma. J Exp Med. 2019:216:1071-90.

114. Cheng H, Dou X, Han JD. Understanding super-enhancers. Sci China Life Sci. 2016:59:277-80

115. Shin HY. Targeting super-enhancers for disease treatment and diagnosis. Mol Cells. 2018;41:506-14.

116. Bao J, Li M, Liang S, Yang Y, Wu J, Zou Q, et al. Integrated high-throughput analysis identifies super enhancers associated with chemoresistance in SCLC. BMC Med Genet. 2019;12:67.

117. Lytle NK, Ferguson LP, Rajbhandari N, Gilroy K, Fox RG, Deshpande A, et al. A Multiscale Map of the Stem Cell State in Pancreatic Adenocarcinoma. Cell. 2019;177:572-586.e522.

118. Veschi V, Verona F, Thiele CJ. Cancer stem cells and neuroblastoma: characteristics and therapeutic targeting options. Front Endocrinol (Lausanne). 2019;10:782.

119. Yokoyama Y, Zhu H, Lee JH, Kossenkov AV, Wu SY, Wickramasinghe JM, et al. BET inhibitors suppress ALDH activity by targeting ALDH1A1 superenhancer in ovarian Cancer. Cancer Res. 2016;76:6320-30.

120. Sharma A, Cao EY, Kumar V, Zhang X, Leong HS, Wong AML, et al. Longitudinal single-cell RNA sequencing of patient-derived primary cells reveals drug-induced infidelity in stem cell hierarchy. Nat Commun. 2018;9:4931.

121. Arfaoui A, Rioualen C, Azzoni V, Pinna G, Finetti P, Wicinski J, et al. A genome-wide RNAi screen reveals essential therapeutic targets of breast cancer stem cells. EMBO Mol Med. 2019;11(10):e9930.

122. Yuan S, Norgard RJ, Stanger BZ. Cellular plasticity in Cancer. Cancer Discov. 2019;9:837-51. 
123. Vicente-Duenas C, Gutierrez de Diego J, Rodriguez FD, Jimenez R, Cobaleda C. the role of cellular plasticity in cancer development. Curr Med Chem. 2009;16:3676-85

124. Nieto MA, Huang RY, Jackson RA, Thiery JP. Emt: 2016. Cell. 2016;166:21-45.

125. Byers LA, Diao L, Wang J, Saintigny P, Girard L, Peyton M, et al. An epithelial-mesenchymal transition gene signature predicts resistance to EGFR and PI3K inhibitors and identifies AxI as a therapeutic target for overcoming EGFR inhibitor resistance. Clin Cancer Res. 2013;19:279-90.

126. Sequist LV, Waltman BA, Dias-Santagata D, Digumarthy $S$, Turke AB, Fidias $P$, et al. Genotypic and histological evolution of lung cancers acquiring resistance to EGFR inhibitors. Sci Transl Med. 2011:3:75ra26.

127. Meacham CE, Morrison SJ. Tumour heterogeneity and cancer cell plasticity. Nature. 2013;501:328-37.

128. Yu HA, Arcila ME, Rekhtman N, Sima CS, Zakowski MF, Pao W, et al. Analysis of tumor specimens at the time of acquired resistance to EGFR-TKI therapy in 155 patients with EGFR-mutant lung cancers. Clin Cancer Res. 2013;19: 2240-7

129. Lomberk G, Blum Y, Nicolle R, Nair A, Gaonkar KS, Marisa L, et al. Distinct epigenetic landscapes underlie the pathobiology of pancreatic cancer subtypes. Nat Commun. 2018;9:1978.

130. Gerrard DL, Boyd JR, Stein GS, Jin VX, Frietze S. Disruption of broad epigenetic domains in PDAC cells by HAT inhibitors. Epigenomes. 2019; 3(2): 11.

131. Su Y, Subedee A, Bloushtain-Qimron N, Savova V, Krzystanek M, Li L, et al. Somatic cell fusions reveal extensive heterogeneity in basal-like breast Cancer. Cell Rep. 2015;11:1549-63.

132. Biehs B, Dijkgraaf GJP, Piskol R, Alicke B, Boumahdi S, Peale F, et al. A cell identity switch allows residual BCC to survive hedgehog pathway inhibition. Nature. 2018;562:429-33.

133. Adam RC, Yang H, Ge Y, Lien WH, Wang P, Zhao Y, et al. Temporal layering of signaling effectors drives chromatin remodeling during hair follicle stem cell lineage progression. Cell Stem Cell. 2018;22:398-413 e397.

134. Nishida J, Momoi Y, Miyakuni K, Tamura Y, Takahashi K, Koinuma D, et al. Epigenetic remodelling shapes inflammatory renal cancer and neutrophildependent metastasis. Nat Cell Biol. 2020;22:465-75.

135. Noel P, Hussein S, Ng S, Antal CE, Lin W, Rodela E, et al. Triptolide targets super-enhancer networks in pancreatic cancer cells and cancer-associated fibroblasts. Oncogenesis. 2020;9:100

136. Leung VY, Gao B, Leung KK, Melhado IG, Wynn SL, Au TY, et al. SOX9 governs differentiation stage-specific gene expression in growth plate chondrocytes via direct concomitant transactivation and repression. PLoS Genet. 2011;7:e1002356.

137. Kadaja M, Keyes BE, Lin M, Pasolli HA, Genander M, Polak L, et al. SOX9: a stem cell transcriptional regulator of secreted niche signaling factors. Genes Dev. 2014;28:328-41.

138. Martini S, Bernoth K, Main H, Ortega GD, Lendahl U, Just U, et al. A critical role for Sox9 in notch-induced astrogliogenesis and stem cell maintenance. Stem Cells. 2013:31:741-51.

139. Nakamura Y, Hattori N, lida N, Yamashita S, Mori A, Kimura K, et al. Targeting of super-enhancers and mutant BRAF can suppress growth of BRAF-mutant colon cancer cells via repression of MAPK signaling pathway. Cancer Lett. 2017:402:100-9.

140. Kuroda J, Tsukamoto T, Nakahata S, Morishita K, Sato R, Kanai A, et al. Genome-wide analysis of BRD4-targets reveals the therapeutic relevance of simultaneous targeting of BCR pathway and IKZF-MYC Axis in mantle cell lymphoma. BLOOD. 2018;132(Supplement 1):4100.

141. Schafer JM, Lehmann BD, Gonzalez-Ericsson PI, Marshall CB, Beeler JS, Redman LN, et al. Targeting MYCN-expressing triple-negative breast cancer with BET and MEK inhibitors. Sci Transl Med. 2020;12(534):eaaw8275.

142. Klingbeil $O$, Lesche R, Gelato KA, Haendler B, Lejeune P. Inhibition of BET bromodomain-dependent XIAP and FLIP expression sensitizes KRASmutated NSCLC to pro-apoptotic agents. Cell Death Dis. 2016;7:e2365.

143. Cui J, Liu J, Fan L, Zhu Y, Zhou B, Wang Y, et al. A zinc finger family protein, ZNF263, promotes hepatocellular carcinoma resistance to apoptosis via activation of ER stress-dependent autophagy. Transl Oncol. 2020;13:100851.

144. Wei L, Wang $X$, Lv L, Liu J, Xing H, Song Y, et al. The emerging role of microRNAs and long noncoding RNAs in drug resistance of hepatocellular carcinoma. Mol Cancer. 2019;18:147

145. Shi W, Zhang C, Ning Z, Hua Y, Li Y, Chen L, et al. Long non-coding RNA LINC00346 promotes pancreatic cancer growth and gemcitabine resistance by sponging miR-188-3p to derepress BRD4 expression. J Exp Clin Cancer Res. 2019;38:60.

146. Suzuki HI, Young RA, Sharp PA. Super-enhancer-mediated RNA processing revealed by integrative MicroRNA network analysis. Cell. 2017;168:1000-14 e1015.

147. Jiang Y, Jiang YY, Xie JJ, Mayakonda A, Hazawa M, Chen L, et al. Coactivation of super-enhancer-driven CCAT1 by TP63 and SOX2 promotes squamous cancer progression. Nat Commun. 2018;9:3619.

148. Xu S, Wan L, Yin H, Xu H, Zheng W, Shen M, et al. Long noncoding RNA Linc00152 functions as a tumor propellant in pan-Cancer. Cell Physiol Biochem. 2017:44:2476-90.

149. Wen S, He Y, Wang L, Zhang J, Quan C, Niu Y, et al. Aberrant activation of super enhancer and choline metabolism drive antiandrogen therapy resistance in prostate cancer. Oncogene. 2020;39:6556-71.

150. Nagasawa M, Tomimatsu K, Terada K, Kondo K, Miyazaki K, Miyazaki M, et al. Long non-coding RNA MANCR is a target of BET bromodomain protein BRD4 and plays a critical role in cellular migration and invasion abilities of prostate cancer. Biochem Biophys Res Commun. 2020;526:128-34.

151. Moreau PR, Ord T, Downes NL, Niskanen H, Bouvy-Liivrand M, Aavik E, et al. Transcriptional profiling of hypoxia-regulated non-coding RNAs in human primary endothelial cells. Front Cardiovasc Med. 2018:5:159.

152. Li P, Zhang X, Wang H, Wang L, Liu T, Du L, et al. MALAT1 is associated with poor response to Oxaliplatin-based chemotherapy in colorectal Cancer patients and promotes Chemoresistance through EZH2. Mol Cancer Ther. 2017;16:739-51.

153. Lin X, Spindler TJ, de Souza Fonseca MA, Corona RI, Seo JH, Dezem FS, et al. Super-Enhancer-Associated LncRNA UCA1 Interacts Directly with AMOT to Activate YAP Target Genes in Epithelial Ovarian Cancer. iScience. 2019;17: 242-55

154. Bonnans C, Chou J, Werb Z. Remodelling the extracellular matrix in development and disease. Nat Rev Mol Cell Biol. 2014;15:786-801.

155. Sharma P, Hu-Lieskovan S, Wargo JA, Ribas A. Primary, adaptive, and acquired resistance to Cancer immunotherapy. Cell. 2017;168:707-23.

156. Vinay DS, Ryan EP, Pawelec G, Talib WH, Stagg J, Elkord E, et al. Immune evasion in cancer: Mechanistic basis and therapeutic strategies. Semin Cancer Biol. 2015:35 Suppl:S185-98.

157. Goodman A, Patel SP, Kurzrock R. PD-1-PD-L1 immune-checkpoint blockade in B-cell lymphomas. Nat Rev Clin Oncol. 2017;14:203-20.

158. Xu Y, Wu Y, Zhang S, Ma P, Jin X, Wang Z, et al. A Tumor-Specific SuperEnhancer Drives Immune Evasion by Guiding Synchronous Expression of PD-L1 and PD-L2. Cell Rep. 2019;29:3435-3447.e3434.

159. Oldenborg PA. CD47: a cell surface glycoprotein which regulates multiple functions of hematopoietic cells in health and disease. ISRN Hematol. 2013; 2013:614619.

160. Betancur PA, Abraham BJ, Yiu YY, Willingham SB, Khameneh F, Zarnegar M, et al. A CD47-associated super-enhancer links pro-inflammatory signalling to CD47 upregulation in breast cancer. Nat Commun. 2017:8:14802.

161. Yang H, Schramek D, Adam RC, Keyes BE, Wang P, Zheng D, et al. ETS family transcriptional regulators drive chromatin dynamics and malignancy in squamous cell carcinomas. Elife. 2015;4:e10870.

162. Dzobo K, Senthebane DA, Thomford NE, Rowe A, Dandara C, Parker MI. Not everyone fits the Mold: Intratumor and Intertumor heterogeneity and innovative Cancer drug design and development. OMICS. 2018;22:17-34.

163. Kelly $A D$, Issa JJ. The promise of epigenetic therapy: reprogramming the cancer epigenome. Curr Opin Genet Dev. 2017:42:68-77.

164. See YX, Wang BZ, Fullwood MJ. Chromatin interactions and regulatory elements in Cancer: from bench to bedside. Trends Genet. 2019;35:145-58.

165. Dawson MA, Kouzarides T, Huntly BJ. Targeting epigenetic readers in cancer. N Engl J Med. 2012;367:647-57.

166. Benton CB, Fiskus W, Bhalla KN. Targeting histone acetylation: readers and writers in leukemia and Cancer. Cancer J. 2017;23:286-91.

167. Huang W, Zheng $X$, Yang Y, Wang $X$, Shen Z. An overview on small molecule inhibitors of BRD4. Mini Rev Med Chem. 2016;16:1403-14.

168. Zuber J, Shi J, Wang E, Rappaport AR, Herrmann H, Sison EA, et al. RNAi screen identifies Brd4 as a therapeutic target in acute myeloid leukaemia. Nature. 2011:478:524-8.

169. Shi X, Liu C, Liu B, Chen J, Wu X, Gong W. JQ1: a novel potential therapeutic target. Pharmazie. 2018;73:491-3.

170. Liu J, Duan Z, Guo W, Zeng L, Wu Y, Chen Y, et al. Targeting the BRD4/ FOXO3a/CDK6 axis sensitizes AKT inhibition in luminal breast cancer. Nat Commun. 2018:9:5200 
171. Zanconato F, Battilana G, Forcato M, Filippi L, Azzolin L, Manfrin A, et al. Transcriptional addiction in cancer cells is mediated by YAP/TAZ through BRD4. Nat Med. 2018;24:1599-610.

172. Neri P, Tagoug I, Maity R, Babich J, Lockwood L, Keats JJ, et al. IKZF1 regulates BRD4 retention and Recruitement at enhancer in myeloma cells: role of BRD4 in IMiDs resistance. BLOOD. 2016;128(22):358.

173. Shu S, Lin CY, He HH, Witwicki RM, Tabassum DP, Roberts JM, et al. Response and resistance to BET bromodomain inhibitors in triple-negative breast cancer. Nature. 2016;529:413.

174. Yashiro-Ohtani Y, Wang H, Zang C, Arnett KL, Bailis W, Ho Y, et al. Longrange enhancer activity determines Myc sensitivity to notch inhibitors in T cell leukemia. Proc Natl Acad Sci U S A. 2014;111:E4946-53.

175. Chen Y, Xu L, Mayakonda A, Huang ML, Kanojia D, Tan TZ, et al. Bromodomain and extraterminal proteins foster the core transcriptional regulatory programs and confer vulnerability in liposarcoma. Nat Commun. 2019;10:1353.

176. Sahai V, Kumar K, Knab LM, Chow CR, Raza SS, Bentrem DJ, et al. BET bromodomain inhibitors block growth of pancreatic cancer cells in threedimensional collagen. Mol Cancer Ther. 2014;13:1907-17.

177. Sun B, Fiskus W, Qian Y, Rajapakshe K, Raina K, Coleman KG, et al. BET protein proteolysis targeting chimera (PROTAC) exerts potent lethal activity against mantle cell lymphoma cells. Leukemia. 2018;32:343-52.

178. Struhl K. Histone acetylation and transcriptional regulatory mechanisms. Genes Dev. 1998;12:599-606.

179. Calo E, Wysocka J. Modification of enhancer chromatin: what, how, and why? Mol Cell. 2013;49:825-37.

180. Sugiura M, Sato H, Kanesaka M, Imamura $Y$, Sakamoto S, Ichikawa T, et al. Epigenetic modifications in prostate cancer. Int J Urol. 2020;28(2):140-9.

181. Loven J, Hoke HA, Lin CY, Lau A, Orlando DA, Vakoc CR, et al. Selective inhibition of tumor oncogenes by disruption of super-enhancers. Cell. 2013; 153:320-34.

182. Zhang X, Wang Y, Chiang HC, Hsieh YP, Lu C, Park BH, et al. BRCA1 mutations attenuate super-enhancer function and chromatin looping in haploinsufficient human breast epithelial cells. Breast Cancer Res. 2019;21:51.

183. Rabe M, Dumont S, Alvarez-Arenas A, Janati H, Belmonte-Beitia J, Calvo GF, et al. Identification of a transient state during the acquisition of temozolomide resistance in glioblastoma. Cell Death Dis. 2020;11:19.

184. Natsume A, Hirano M, Ranjit M, Aoki K, Wakabayashi T. Aberrant transcriptional regulation of super-enhancers by RET finger protein-histone deacetylase 1 complex in glioblastoma: Chemoresistance to Temozolomide. Neurol Med Chir (Tokyo). 2019;59(8):293-8.

185. Yang Y, Zhao Y, Liao W, Yang J, Wu L, Zheng Z, et al. Acetylation of FoxO1 activates Bim expression to induce apoptosis in response to histone deacetylase inhibitor depsipeptide treatment. Neoplasia. 2009;11:313-24.

186. Ohtani Y, Xu S, Petrovic J, Xu L, Aster JC, Pear WS. Modular domains within a super enhancer Determine drug resistance in leukemia. BLOOD. 2015; 126(23):44.

187. Pear W, Yashiro-Ohtani Y, Petrovic J, Yu S, Mercado V, Xu L, et al. Modular domains within a super enhancer DETERMINE drug resistance in t-cell acute lymphoblastic leukemia. Exp Hematol. 2016;441:S25.

188. Galbraith MD, Bender H, Espinosa JM. Therapeutic targeting of transcriptional cyclin-dependent kinases. Transcription. 2019;10:118-36.

189. Roskoski R Jr. Cyclin-dependent protein serine/threonine kinase inhibitors as anticancer drugs. Pharmacol Res. 2019;139:471-88.

190. Pelish HE, Liau BB, Nitulescu TA II, Poss ZC, Da Silva DH, et al. Mediator kinase inhibition further activates super-enhancer-associated genes in AML. Nature. 2015;526:273-6.

191. Zhao X, Ren Y, Lawlor M, Shah BD, Park PMC, Lwin T, et al. BCL2 Amplicon Loss and Transcriptional Remodeling Drives ABT-199 Resistance in B Cell Lymphoma Models. Cancer Cell. 2019;35:752-766.e759.

192. Geng M, Yang Y, Cao X, Dang L, Zhang T, Zhang L. Targeting CDK12mediated transcription regulation in anaplastic thyroid carcinoma. Biochem Biophys Res Commun. 2019;520:544-50.

193. Guo L, Li J, Fang S, Lee M, Zeng H, Li T, et al. Synthetic lethality of combinatory inhibition of BET and CDK7 in BET(i) resistant leukemia cells. BLOOD. 2018;132(Supplement 1):1354.

194. Johnson GL. Disrupting adaptive bypass pathways activated by targeted kinase inhibitors. FASEB J. 2016;301.

195. Xiang X, Deng L, Xiong R, Xiao D, Chen Z, Yang F, et al. Tex10 is upregulated and promotes cancer stem cell properties and chemoresistance in hepatocellular carcinoma. Cell Cycle. 2018;17:1310-8.
196. Jeselsohn R, Bergholz JS, Pun M, Cornwell M, Liu W, Nardone A, et al. AlleleSpecific Chromatin Recruitment and Therapeutic Vulnerabilities of ESR1 Activating Mutations. Cancer Cell. 2018;33:173.

197. Nguyen VTM, Barozzi I, Faronato M, Lombardo Y, Steel JH, Patel N, et al. Differential epigenetic reprogramming in response to specific endocrine therapies promotes cholesterol biosynthesis and cellular invasion. Nat Commun. 2015;6:10044.

198. Baumgart SJ, Nevedomskaya E, Lesche R, Newman R, Mumberg D, Haendler B. Darolutamide antagonizes androgen signaling by blocking enhancer and super-enhancer activation. Mol Oncol. 2020;14:2022-39.

199. Ma Q, Yang F, Mackintosh C, Jayani RS, Oh S, Jin C, et al. Super-enhancer redistribution as a mechanism of broad gene dysregulation in repeatedly drug-treated Cancer cells. Cell Rep. 2020;31:107532.

\section{Publisher's Note}

Springer Nature remains neutral with regard to jurisdictional claims in published maps and institutional affiliations.
Ready to submit your research? Choose BMC and benefit from:

- fast, convenient online submission

- thorough peer review by experienced researchers in your field

- rapid publication on acceptance

- support for research data, including large and complex data types

- gold Open Access which fosters wider collaboration and increased citations

- maximum visibility for your research: over $100 \mathrm{M}$ website views per year

At BMC, research is always in progress.

Learn more biomedcentral.com/submissions 